\title{
JUAN BAUTISTA CABRERA IVARS: UN REFORMADOR PROTESTANTE EN EL SIGLO XIX ESPAÑOL
}

\author{
POR \\ PATROCINIO Ríos SÁNCHEZ ${ }^{1}$ \\ Institutos de Enseñanza Secundaria y Middlebury College (Madrid y Vermont, EE. UU.). Jubilado
}

\begin{abstract}
RESUMEN
El trabajo presenta, siguiendo un criterio cronoespacial, una síntesis de la biografía de Juan Bautista Cabrera Ivars, precedida de una breve descripción del ordenamiento jurídico en que transcurre. Se presta atención particular a la obra organizativa y reformista y se destaca el hecho novedoso de haber sido elegido miembro de la Hispanic Society of America. En el cuerpo del texto se reproducen algunos documentos inéditos y en apéndice se adjunta una clasificación de la obra escrita, surgida casi toda ella del impulso reformador y como complemento de tal empresa, y una estadística del desarrollo del protestantismo en España.
\end{abstract}

PALABRAS CLAVE: Juan Bautista Cabrera Ivars; reformador protestante; obra escrita; siglo XIX; España; estadística; Hispanic Society of America.

\section{JUAN BAUTISTA CABRERA IVARS: A PROTESTANT REFORMER IN THE SPANISH NINETEENTH CENTURY}

\begin{abstract}
This article synthesizes the biography of Juan Bautista Cabrera Ivars within the legal context of the period. It underlines Cabrera's role as both an organizer and a reformer and introduces the novelty of his election as a member of the prestigious Hispanic Society of America. A number of previously unpublished documents are included within the article; likewise, in the appendix, the author classifies Cabrera's written works, almost all of which resulted from his fervor as a reformer, and gives statistics of the growth of Protestantism in Spain from the sixteenth century until today.

KEY WORDS: Juan Bautista Cabrera Ivars; Spanish reformer; Works; Protestantism; Nineteenth century; Spain; Statistic; Hispanic Society of America.
\end{abstract}

Cómo CITAR ESTE ARTículo / CITATION: Ríos Sánchez, P. 2018. «Juan Bautista Cabrera Ivars: un reformador protestante en el siglo XIX español». Hispania Sacra 70, 141: 157-181. https://doi.org/10.3989/hs.2018.015

Juan Bautista Cabrera (1837-1916) es la figura más singular del periodo que los historiadores que se ocupan del protestantismo español denominan Segunda Reforma, fenómeno que comienza a desarrollarse con la Revolución de 1868 y que terminaría en 1936. La trayectoria existencial de este reformador español abarca un periodo de casi 80 años, que transcurren bajo tres diferentes formas de gobierno constitucional del Estado español.

\footnotetext{
1 jlramw@telefonica.net / ORCID iD: http://orcid.org/0000-0003-
} 3402-3342
La primera abarca el tercio central del siglo XIX, delimitado en un lado por la Constitución de 1837, confesional pero proteccionista y tolerante, según el padre Gabriel del Estal2, lo que explica la llegada de los primeros misioneros en la época regente de María Cristina; y en el otro extremo, por la Revolución de 1868 y la Constitución de 1869. Entre medias se suceden la Constitución de 1845, confesionalmente católica, y el Concordato de 1851, que 
desde el Vaticano refuerza la unidad y la confesionalidad católica del Estado al declarar que la religión católica «sigue siendo la única de la Nación española». Este periodo lleva, salvo los ocho años de tolerancia que ampara la primera y breve Constitución citada, la marca característica de falta de libertad religiosa.

La Constitución de 1869 abre una nueva situación legal para los acatólicos. Afirma Del Estal que en su artículo 21 «recibe por primera vez consagración política expresa la libertad de cultos». ${ }^{3}$ Quedaba formulado así:

La nación se obliga a mantener el culto y los ministros de la religión católica.

El ejercicio público o privado de cualquiera otro culto queda garantizado a todos los extranjeros residentes en España, sin más limitaciones que las reglas universales de la moral y del derecho.

Si alguno de los españoles profesaren otra religión que la católica, es aplicable a los mismos todo lo dispuesto en el párrafo anterior. ${ }^{4}$

Aunque también de breve duración, pues termina con la de 1876, constituye uno de esos paréntesis históricos de libertad otorgada. En palabras de Del Estal, «El culto no católico, así privado como público, no constituye por sí y en cuanto tal ningún delito». ${ }^{5}$ Pero el golpe del general Martínez Campos en Sagunto a fines de noviembre de 1874 y la restauración borbónica en la persona de Alfonso XII abren otra época bien distinta en cuanto a política religiosa. La libertad concedida de la etapa anterior se reduce durante la Restauración a una cicatera tolerancia. El artículo 11 de la nueva Constitución, promulgada en 1876 y vigente hasta 1931, declaraba:

La religión Católica, Apostólica, Romana, es la del Estado. La nación se obliga a mantener el culto y sus ministros.

Nadie será molestado en el territorio español por sus opiniones religiosas ni por el ejercicio de su respectivo culto, salvo el respeto debido a la moral cristiana.

No se permitirán sin embargo otras ceremonias ni manifestaciones públicas que las de la religión del Estado. $^{6}$

Este nuevo marco legal responde a la forma de Estado "confesional semitolerante»: sólo se permite como culto público el católico, pues «el culto público no católico es políticamente un delito». ${ }^{7}$

Por otra parte, el citado Concordato de 1851, marco bilateral de relación entre la Iglesia y el Estado, confesionalmente católico e intolerante o excluyente de cualquier culto no católico como disponía en su artículo 1, discurre a lo largo de un siglo largo (hasta 1953), salvo la crisis breve de la Segunda República. La efímera Constitución de esta nueva época que, promulgada el 9 de diciembre de 1931, sustituye a la restrictiva de 1876, adopta en materia religiosa un carácter anticonfesional y laicista; pero su vigencia sobrepasa ya la cronología existencial de Juan Bautista Cabrera.

\footnotetext{
3 Ibídem: 319.

4 González-Ares 2015: 188.

5 Del Estal 1981: 318.

6 González-Ares 2015: 216.

7 Del Estal 1981: 315.
}

\section{CABRERA CATÓLICO}

Las ocho décadas de su vida se pueden fragmentar en dos grandes etapas: la católica, desde su nacimiento en 1837 hasta agosto de 1863; y la protestante y reformista, que comienza cuando rompe con la Orden calasancia en el verano de ese año 1863 y termina con su fallecimiento el 18 de mayo de 1916.

Esta segunda parte, de más larga duración (53 años), es también la más rica y permite las siguientes subdivisiones siguiendo un criterio cronoespacial: Gibraltar (agosto de 1863-29 de septiembre de 1868), Sevilla (29 de septiembre de 1868-19 de noviembre de 1874) y Madrid (19 de noviembre de 1874-18 de mayo de 1916).

Juan Bautista Cabrera Ivars nació en Benisa (Alicante) el día 23 de abril de 1837. Fue bautizado al día siguiente en la parroquia de San Pedro Apóstol. ${ }^{8}$ Sus padres, Salvador Cabrera y Peris y María Magdalena Ivars Ivars, formaban una familia católica piadosa y de condición social humilde con cuatro hijos y dos hijas. Juan Bautista fue el mayor.

El mismo Cabrera dejó constancia de esa fe y de esa piedad católica y sencilla de sus padres en la primera sección del Canto memorial, publicado póstumamente en 1917. También confiesa allí que desde pequeño tuvo gran devoción y participó férvidamente en servicios religiosos:

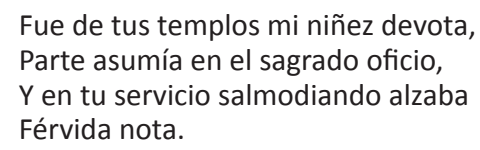

La devoción confesada, gozosa y partícipe de las funciones religiosas (novenas, procesiones, plegarias...) le impulsó a romper lazos con el mundo para ingresar en la Orden de las Escuelas Pías. A los «tres lustros», como dice de sí mismo, entró como novicio y permaneció como tal entre 1852 y 1853 . El día 19 de noviembre de ese año de 1853 en que finaliza el noviciado, el joven Juan Cabrera de la Purísima Concepción hizo voto de «paupertatem, castitatem et obedientiam» ante el comisario apostólico Jacinto Feliu. Así consta, y con ese nombre, en el acta que sobre este asunto he podido consultar en el archivo personal de Rosario Morales Cabrera, cuya cortesía agradezco.

Cabrera, por este compromiso, quedaba estrechamente ligado a la Orden. En 1853 pasó de Valencia al colegio que la Institución escolapia tenía en Albarracín (Teruel) para los jóvenes de Valencia. Aquí realizará durante cuatro años los estudios eclesiásticos preceptivos antes de recibir otros grados superiores.

Cumplidos esos cuatro años de estudios en Albarracín, regresa a Valencia en 1857 y le destinan como maestro a una escuela de párvulos en Gandía. Allí permanece un año (1857-1858) porque le trasladaron a Valencia para poner en marcha una escuela de enseñanza superior (1858-1859). En 1859 se traslada de nuevo a Gandía para montar otra

8 He tenido ocasión de consultar el Certificado de la Partida de Bautismo, firmado por el presbítero Jacinto Ribes, archivero de la iglesia de parroquial de San Pedro Apóstol de Benisa, quien da fe de que, según el libro de bautismos de esta parroquia, Juan Bautista Cabrera fue bautizado por Vicente Marco el 24 de abril de 1837 y que nació «a las nueve de la noche del día anterior». Actuaron como padrinos Francisco Ivars y María Cabrera. El archivero firma el certificado el 26 de septiembre de 1902. 
de esta misma clase y aquí residirá hasta 1863. La empresa educativa encomendada resultó exitosa en ambos lugares. El historiador levantino Manuel Rico García afirma que «en este Colegio [de Gandía] y dirigiendo la indicada escuela, pasó el Sr. Cabrera por espacio de cuatro años, durante los cuales levantó la instrucción a una envidiable altura». ${ }^{9}$

Cabrera, pues, ha vuelto desde Albarracín a la zona levantina cuando tiene 20 años e irá recibiendo sucesivamente las distintas órdenes sagradas. Según los documentos originales que he podido consultar, le confirió la ordenación al subdiaconado el arzobispo de Valencia Pablo García Abella el día 3 de septiembre de 1858 y fue ordenado diácono por el obispo de Segorbe el día 16 de marzo de 1861. Un año después, el 15 de marzo de 1862 concretamente, recibió las órdenes de presbítero de manos del arzobispo de Valencia Mariano Barrio Fernández. En agosto de 1863 abandona la Orden y emigra a Gibraltar.

FIGURA 1

Ordenación de Cabrera al presbiterado el 15 de marzo de 1862

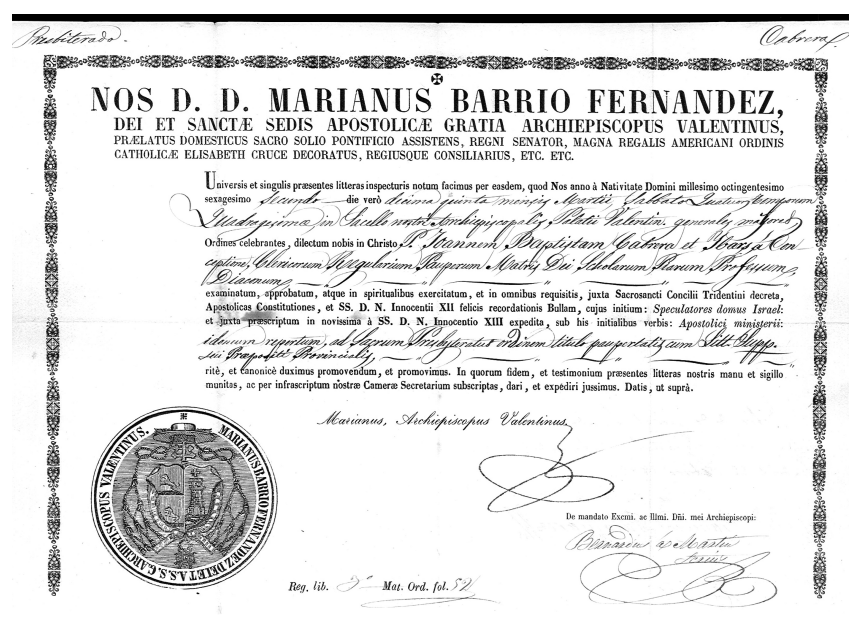

\section{LA RUPTURA Y SUS CAUSAS}

Con estos versos cierra Cabrera la sección VIII de Canto memorial: «me expatrié cuando mediaba el año/ sesenta y tres del siglo diecinueve». En el verso 5 de la secuencia siguiente se hace un poco más precisa la fecha de la expatriación: "era una tarde de agosto, canícula en pleno». Salió del puerto de Alicante. A popa quedaba su promontorio. Llevaba el corazón dividido por las consecuencias que se derivaban de esa emigración. En la sección IX describe su estado de ánimo:

\footnotetext{
Unas veces franco gozo embargaba mi pecho, Viéndome a salvo del fanatismo odioso; Y otras veces, al pensar en la patria querida Con honda pena se entristecía el alma. Posición social, carrera, parientes y amigos, Afectos puros y aspiraciones nobles, Todo a un tiempo se perdía quizá para siempre, Y todo a cambio de un porvenir oscuro. ¡Cuán aislado y cuán solo, si no me ofreciera Un pecho amante su virginal cariño!
}

Los factores que determinan la ruptura del vínculo con las Escuelas Pías son varios. Uno, la lectura y atento estudio de la Escritura siendo estudiante en Albarracín; otro, la causa que se sigue desde 1860 a 1863 contra un grupo de protestantes españoles: en la primavera de este año, Manuel Matamoros, José Alhama, Miguel Trigo, Antonio Carrasco y otros protestantes, encausados por serlo, salían de la cárcel de Granada con dirección a Málaga, donde unidos a otros presos embarcaron con destino a Gibraltar para cumplir la pena de destierro, que conmutaba la de prisión, tras un resonante proceso que traspasó las fronteras españolas. Y en tercer lugar, no debió de ser ajeno a los dos factores anteriores el amor humano, según el último verso citado. ${ }^{10}$ Cabrera no ocultaba en su biografía rimada que Josefa Latorre (1842-1923), maestra de primeras letras en Fuente la Higuera, le acompañaba en la expatriación. La Escritura, examinada con atención, no prohibía, en efecto, ese amor. Y más tarde defendió esta idea en El celibato forzoso del clero (Sevilla, 1870). En Gibraltar contraerá matrimonio, entrará en contacto con la comunidad protestante y gestionará la promoción de una Reforma para España que empezará a hacerse realidad primero en Sevilla tras la Revolución de 1868.

El propio Cabrera también ha dejado testimonio personal de la lectura de la Biblia en Canto memorial, sección II. Cursaba estudios en Albarracín y refiere que:
Un día el Superior, para apartarme De la literatura,
Tuvo a bien ocho tomos entregarme De la Santa Escritura.

La lectura le abrió la perspectiva cristocéntrica. En la sección IV asevera taxativo: "Sólo vale de Cristo la mediación». A este verso, tan netamente protestante y piedra angular de su nueva manera de vivir la fe, siguen estos otros de la misma índole. La voz lírica se dirige a Dios en actitud de apóstrofe:
Esto hallé en tu Palabra. Mas iay!, en vano Sacerdotes y misas allí busqué; Purgatorio, indulgencias, mérito humano Y otros dogmas tampoco encontré. Invadieron las dudas de lleno el alma, Y quedó en angustiosa perplejidad: ¿Cómo hacerla tornar a la dulce calma, Recobrar la perdida tranquilidad?

El joven escolapio Cabrera se pregunta en la sección $V$ de su biografía versificada:

10 En este sentido apuntan los benisseros Bernat Capó y Juan José Cardona Ivars, compiladores de una Antología de escritores benisseros, aunque parece que en ellos el motivo sentimental fue la única causa de la ruptura de Cabrera con la Orden Calasancia. Desconocen o desatienden en este trabajo los factores teológicos. Escriben: «Ya ordenado [Cabrera] se trasladó a Gandía donde el amor humano se cruzó en su camino. La dispensa solicitada no le fue concedida y el joven Juan Bautista hubo de abandonar la grey escolapia e incluso la propia patria para poder contraer matrimonio, fruto del cual fueron siete hijos» (Capó y Cardona 1985: 41). Y Bernardo Capó, luego Bernat, había escrito antes: "Quería compaginar sus dos amores, el divino y el humano, pero sus superiores se mostraron intransigentes [...]. Cabrera solicitó del Papa la correspondiente dispensa para abandonar la orden y contraer matrimonio, pero Pío IX no era el pontífice más adecuado para otorgar facilidades [...]. No quería dejar el sacerdocio, no deseaba abandonar su educación y tampoco a su enamorada. Halló la solución integrándose en la iglesia evangelista Reformada» (Capó 1979: 133).

\footnotetext{
9 Rico García 1889: 220.
} 
¡La Tradición! Concilios, Santos Padres,

Teólogos, Doctores y Jerarcas

Infalibles... ¿qué valen todos ellos

Con la Santa Escritura comparados?

Tras las críticas reflexiones realizadas, toma una decisión firme, según rezan estos dos versos con los que cierra la sección V: «determiné admitir tan solamente/ lo que tu Santo libro me enseñase».

De la categórica determinación se derivaba una cuestión de conciencia, oscilante entre la hipocresía que supone mantenerse como escolapio y la ruptura radical con la Orden: fingir creer lo que no cree o confesar resueltamente su nueva convicción y ser tachado de hereje. En esta tesitura se encontraba cuando estalla el resonante proceso y condena de los protestantes por la Audiencia de Granada. ${ }^{11}$

La prensa española informó de tal suceso, con cierta amplitud en algún caso, como el del diario El Clamor Público ${ }^{12}$, y adquirió trascendencia internacional pues se llevaron a cabo intervenciones promovidas desde el extranjero en favor de los presos protestantes encausados por delitos contra la religión. Comisiones de cristianos evangélicos de países como Inglaterra, Suiza, Francia, Holanda, Rusia, Austria, Suecia y Dinamarca abogaron con sus solicitudes en favor de los presos españoles perseguidos por sus creencias religiosas. ${ }^{13}$ En este sentido el diario $L a$ España del 30 de abril de 1863 publica la correspondencia recibida de Granada el 24 del mismo mes bajo el título «El protestantismo en España». Comenzaba de esta manera:

Ayer se vio en la audiencia la causa de los protestantes Alhama, Matamoros y Trigo, célebre por la parte que en ella han tomado sus correligionarios ingleses $y$ alemanes, y por haber arrancado de sus ocupaciones domésticas a 36.000 damas francesas, para solicitar a S. M. la Reina católica el perdón de los acusados.

Cabrera parece que estaba al tanto de lo que ocurría con los disidentes o "herejes» encausados y condenados de Granada y de Málaga. Con ellos iba a coincidir luego en Gibraltar. Menciona sus nombres en Canto memorial y dice que su «enorme delito consistía/ en que las santas Páginas leyeron». Viéndose en situación semejante, Cabrera, ya presbítero escolapio, prepara su «evasión» de España. Finaliza la sección VII de Canto memorial con estos versos:

En tales circunstancias,

La inquisición civil del fanatismo,

Sancionando las fieras arrogancias,

¿Qué podía yo hacer? ¿A quién consejo

11 Fernando Garrido (1821-1883) resume la acusación y defensa del proceso (Garrido 1881: 77-127).

12 «Procesos sobre propaganda protestante» titula la noticia que en relación con los encausados publica este periódico en la sección de tribunales del viernes 29 de noviembre de 1861. Reproduce el escrito del fiscal (3). Sobre el mismo asunto, también La Esperanza del 4 de mayo de 1863 (3).

13 Fernando Garrido reproduce parte de los documentos enviados a la reina Isabel y procedentes de diversas instancias y no sólo protestantes; también católicos holandeses. Entre otras peticiones, la de la Alianza Evangélica de Gran Bretaña, la de las iglesias evangélicas de Austria, la de señoras holandesas y la de la Sociedad de Amigos, comúnmente conocidos como cuáqueros (Garrido 1881: 128-143). Véase también Vilar (2002: 87-99) sobre uno de los más importantes encausados, Manuel Matamoros; y García Rubio 1994: 128-132.
Pedir de mi ansiedad en el abismo,

En asunto tan arduo y tan complejo?

$[\ldots]$

Con cautela y sigilo

Mi evasión preparé, seguro asilo

Esperando encontrar en tierra extraña

Más libre y menos rábida que España. ${ }^{14}$

Cabrera se encontraba en un dilema: desmentirse a sí mismo, cerrar los ojos a su nueva visión cristocéntrica, es decir, abjurar íntimamente, o huir. Obró en conciencia.

El citado historiador Rico García traza una semblanza muy ajustada de Cabrera y expone la cuestión de los protestantes:

La causa que por entonces se formó (1860 al 63) contra algunas personas de Málaga y Granada, acusadas de protestantes, le indujo [a Cabrera] a estudiar más detenidamente la cuestión religiosa; y con este estudio, no solo se confirmaron sus disidencias, sino que en su concepto adquirió el convencimiento de que aquellos acusados de protestantes tenían razón, y que en la Iglesia se necesitaba una reforma radical. ${ }^{15}$

Otros autores posteriores, como García Rubio ${ }^{16}$ y Benito Corvillón junto con Daniel Vidal ${ }^{17}$, piensan que Cabrera "había mantenido correspondencia» con algunos procesados. ${ }^{18}$ Pero, como dice el profesor Vilar, aún está por establecer si Cabrera había mantenido entonces correspondencia con los condenados en Granada. ${ }^{19}$ Sí es cierto, en cambio, que después, estando ya en Gibraltar, dirigió a Manuel Matamoros una carta, importante por varias razones, el 30 de mayo de 1866, custodiada en el archivo de la Iglesia Evangélica Española (Madrid) y transcrita, con leves alteraciones, por García Rubio. ${ }^{20}$ Más, en este sentido, sólo aduce en ella que "por mis opiniones religiosas tuve que emigrar a este punto». ${ }^{21}$

14 La "cautela y sigilo» con que efectuó la evasión sugieren la forma disfrazada de huir. Según el protestante J. M. Martínez, huyó «con peluca y vestido de paisano» (Martínez 1994: 175). Exactamente igual en Arencón (2000: 128). Mateos-Gago anota algún detalle más en la carta escrita el 20 de septiembre de 1876 y enviada al director de El Siglo Futuro, que la publica dos días después (Mateos-Gago 1876: 2-3). «Disfrazado el Padre de mercader, y con el pseudónimo de D. Ricardo, se encaminó la feliz pareja a Gibraltar, donde le esperaban no pocos desengaños» (en Mateos-Gago 1877: III, 290). En otra carta al director de EI Pensamiento Español, que fechaba el 12 de noviembre de 1869, decía: «Un año después de su ordenación, se fue, fingiéndose comerciante, a Fuente La Higuera, donde la Pepa tenía abierta una academia de niñas [...]» (ibídem: III, 195).

15 Rico García 1889: 221.

16 García Rubio 1994: 144

17 Corvillón y Vidal 1973: 2065.

18 El pastor Arturo Gutiérrez Martín sostiene igualmente, aunque sin citar fuentes, que «la razón de que Juan Bautista Cabrera se refugiase en el Peñón se debió al temor de ser detenido también a raíz del procesamiento de Matamoros y sus amigos, pues siendo presbítero en Valencia mantenía correspondencia con los encausados» (Gutiérrez Martín 1969: 32).

19 Vilar 1994: 374.

20 García Rubio 1994: 144-147.

21 Ibídem: 146. También hace esta importante declaración (me atengo a la carta autógrafa) acerca del medio de llevar a cabo la acción reformadora: «aún no he leído en la historia que haya habido nación alguna en la que se hiciera la reforma por otros que por el clero de la misma nación». Igual relieve alcanza esta otra apreciación sociorreligiosa acerca de su carácter reformador y de la existencia en España de otros presbíteros: «como he pasado hasta hoy, pasaré en adelante, hasta que 
Parece que se manifestó más explícitamente en otra ocasión, según el testimonio que aporta J. A. Wylie (18081890), historiador escocés, en Daybreak in Spain, publicado en 1870. Esta autor británico viajó por distintas ciudades españolas y asistió el tercer domingo de octubre de 1869 a un culto en la capilla de la calle sevillana de las Vírgenes, donde ya oficiaba Cabrera. ${ }^{22}$ Destaca la amplia concurrencia al servicio religioso y la elocuencia del oficiante. ${ }^{23}$ Esboza una breve biografía del exfraile escolapio. Habló con él y recogió esta otra declaración que considero interesante de reproducir. Se refiere al estado atribulado del fraile escolapio con estas palabras:

He obtained a copy of the Scriptures; but the more he read the more he doubted. The conflict in his soul grew greater every day. Of his state at that time he has given us the following picture:

I began to read diligently pious books, and mortified myself frequently with the "cilicio» (an elastic waist-band, covered with sharp points, which all had to wear every Friday; upon drawing a long breath the band tightened, and the points penetrated into the flesh right round the body), and with the imagined consolations of the confession. But all in vain; my heart was dry, my soul in darkness, my eyes continually filled with tears of sorrow and desperation, bitterness and sadness being my lot.

A ray of light shot into the darkness; it was the words: "Come unto me, all ye that labour and are heavy laden, and I will give you rest». ${ }^{24}$

Luego llegó el tiempo del proceso de los protestantes encausados en Granada, que coincidía con la ordenación de Cabrera como presbítero en 1862. Según Wylie, al flamante presbítero alicantino le impresionó la persecución que la Iglesia hacía en nombre del Evangelio y el valor de quienes se habían apartado de ella y habían abrazado el protestantismo, si bien no se menciona la correspondencia aludida por algunos autores. Escribe Wylie:

He [Cabrera] felt that his vow obliged him to go forward, and he received orders from the hands of the Archbishop of Valentia in 1862. It was about this time that the imprisonment of Matamoras [sic] and his companions took place. The eyes of Cabrera, in common with those of his countrymen, were fixed on the spectacle of men suffering bonds and imprisonment for the Gospel. How it affected him he tells us: This event deeply

a Dios le plazca abrir las puertas de España, que es lo que yo deseo, para reunirme con mis compañeros los Presbíteros españoles, de los que hay más protestantes que VV. se figuran» (ibídem: 147). Reproduzco en el apéndice la última página de la carta original autógrafa.

22 Cabrera anota en domingo 27 de diciembre de 1868 en el Diario S1: "se inauguró la Iglesia provisional, en la calle de las Vírgenes de Sevilla. D. Antonio celebró un bautismo, y yo prediqué».

23 Wylie 1870: 286.

24 Ibídem: 295. "Consiguió un ejemplar de las Escrituras, pero cuanto más leía más dudaba. El conflicto espiritual interno aumentaba día tras día. Él mismo nos describe el estado de ánimo de entonces: empecé a leer con avidez libros piadosos y me mortificaba frecuentemente con el cilicio (faja de agudas puntas de hierro ceñida al cuerpo que todos vestíamos cada viernes; al respirar la faja se apretaba alrededor del cuerpo y las puntas penetraban en la carne) y con el imaginado consuelo de la confesión. Pero todo era en vano. Mi corazón estaba seco, mi alma sumida en la oscuridad, mis ojos anegados en lágrimas de desconsuelo y desesperación. Amargura y tristeza eran mi desventura. Estas palabras, como un rayo de luz, disiparon las tinieblas: Venid a mí todos los que estáis trabajados y cargados y yo os haré descansar» (ídem). impressed me, showing in lively colours the cruelty of the Church on the one hand, which persecuted in the name of the Gospel; and on the other the faith and valour of a few men who did not fear persecution in the defence and confession of the Gospel they had embraced. And these were Protestants. This completed the great change; his eyes were fully opened, and he now clearly saw the vanity of the faith in which he had been born, and that the really Apostolic Church was the Protestant one. ${ }^{25}$

FIGURA 2

Fragmento de la carta de Cabrera a M. Matamoros. 30 de mayo de 1866

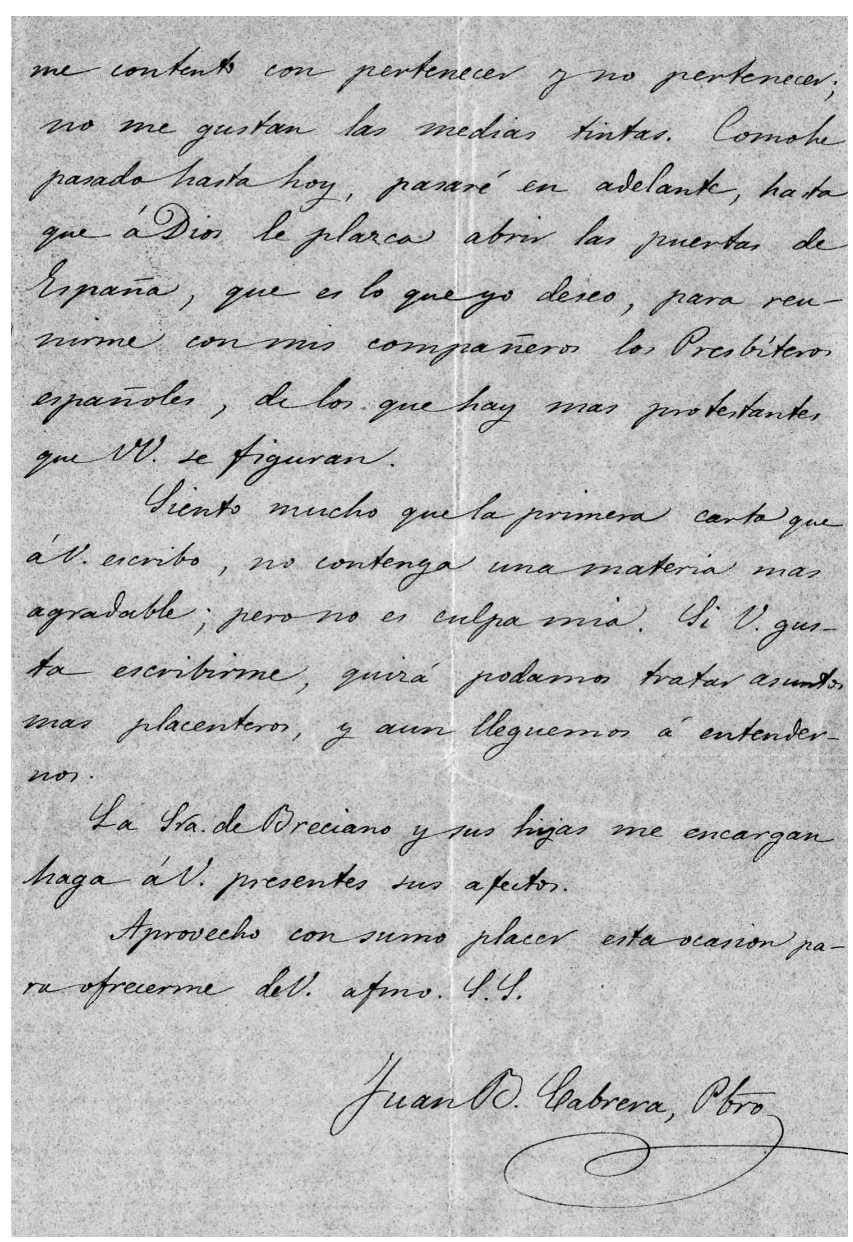

Wylie señala también que por entonces cayó en sus manos un catecismo protestante que le facilitó una concisa presentación doctrinal de esta rama cristiana («a Protestant

25 Wylie 1870: 295-296. «Cabrera sintió que el voto que había tomado le obligaba a seguir adelante y recibió las órdenes sagradas de manos del arzobispo de Valencia en 1862. Fue por entonces cuando tuvo lugar el encarcelamiento de [Manuel] Matamoros [García] y sus compañeros. La mirada de Cabrera, como la de todos sus compatriotas, contempló el espectáculo: unos hombres que sufrían prisión por causa del Evangelio. Él nos cuenta en qué grado le afectó: El acontecimiento me impresionó profundamente. Por un lado se mostraba con viveza la crueldad de la Iglesia, que perseguía en nombre del Evangelio. Por otro, la fe y el valor de unos pocos hombres que no temían la persecución emprendida contra ellos por defender y confesar el Evangelio que habían abrazado. $Y$ estos hombres eran protestantes. Así se completó el cambio. Sus ojos se abrieron completamente y se percató de la vanidad de la fe en la que había nacido y de que la auténtica Iglesia Apostólica era la protestante» (ídem). 
catechism happened to fall in his way»). Así se colmó la decisión final de la ruptura: «His decision was now finally taken, although not without a struggle». ${ }^{26}$ Años más tarde Cabrera declarará directa y taxativamente la causa general de su ruptura con la Iglesia católica. En el número 536 del periódico La Luz, correspondiente al 29 de febrero de 1888 (38), escribió:

Hemos salido de la Iglesia de Roma, no por lo que tiene de cristiana, sino por lo que tiene de pagana. Si dicha Iglesia se desprendiera de este último elemento, si se reformase y purificase en sí misma y por sí misma, ninguna razón tendríamos para haber salido de ella. Porque no lo ha hecho así, hemos salido. ${ }^{27}$

Pero problemas morales, de conciencia personal o de doctrina y circunstancias político-religiosas represoras de la disidencia no serán las razones explicativas que de la ruptura divulguen detractores como Francisco MateosGago Fernández, el sevillano padre Gago (1827-1889), o su simpatizante Menéndez Pelayo. ${ }^{28}$ Para el presbítero Gago, profesor de Hebreo en la Universidad de Sevilla, de la que fue decano, la causa tanto de la Reforma de Lutero como de la separación del padre Cabrera de la Iglesia católica estriba en la cuestión de la carne. Según Gago, desde su confesionalismo hostil y beligerante, la monja Catalina de Bora y Josefa Latorre, la joven con la que Cabrera marchó a Gibraltar y con quien contrajo matrimonio, tuvieron mucho que ver en las respectivas rupturas de lazos eclesiales de ambos «herejes». ${ }^{29}$

\section{CABRERA REFORMADOR}

Decía en un apartado anterior que la etapa protestante o de ruptura comenzó cuando se separó de la Orden calasancia en el verano de ese año 1863. La reformadora propiamente dicha comenzará en Gibraltar y formalmente la fijaré en 1867, pues, por un lado, se hará cargo entonces de la comunidad española; y por otro aparecerá en ese año la primera entrega que Cabrera da a la luz en castellano de Exposición histórica y doctrinal de los Treinta y Nueve Artículos de la Iglesia anglicana de E. H. Browne. Al año siguiente creará el Consistorio.

26 Wylie 1870: 296. Fritz Fliedner, pastor alemán asentado en España, afirmó en la información que bajo el título «The Evangelization of Spain» expuso en la sexta conferencia general de la Alianza Evangélica celebrada en Nueva York entre el 2 y el 12 de octubre de 1873 que el primer contacto de Cabrera con el protestantismo comenzó con la lectura de un catecismo de niños editado en Nueva York. No precisa las circunstancias, simplemente escribe: «Cabrera, formerly a Spanish priest, learned the first word of Protestant doctrine through a Spanish catechism for children, printed in New York» (Fliedner 1874: 125).

27 Serrano 2000: 410.

28 Menéndez Pelayo 1987: II, 995.

29 Desde su animadversión manifiesta hacia los protestantes españoles, Menéndez Pelayo sostiene también en Historia de los heterodoxos la misma causa para explicar la salida de José María Blanco White de la Iglesia católica. Para él, en las herejías «siempre» son determinantes la «lujuria» (1987: II, 791) o las «faldas»: «Prescinda mi lector de la insolente bufonada con que esta cínica confesión termina y aprenda a qué atenerse sobre las teologías y liberalismos de Blanco. ¡Que siempre han de andar faldas de por medio en este negocio de herejías!» (ibídem: II, 799).

\section{Gibraltar (agosto de 1863-29 de septiembre de 1868)}

Cabrera va a permanecer en este enclave británico hasta el 29 de septiembre de 1868. Cinco años. Sin olvidar la Exposición histórica y doctrinal de los Treinta y Nueve Artículos, cuatro hechos importantes deben reseñarse aquí: el matrimonio con Josefa Latorre, el comienzo del pastorado, la creación del Consistorio, germen de la futura Iglesia Española Reformada, y el encuentro con el general Juan Prim.

El matrimonio se celebró el 22 de septiembre de 1863 en la Catedral de Gibraltar. Solemnizó el acto el canónigo y capellán civil Thomas Sleeman en presencia de Pablo Sánchez, Alfred Giolma y Paulino Sánchez. Así consta en el Certificado del Extracto del Registro de Matrimonios conservado en la ciudad de Gibraltar, cuya fotocopia y compulsa he podido consultar en el archivo familiar de Rosario Morales Cabrera. ${ }^{30}$

En Gibraltar comienza a estudiar inglés, "sin profesores», según consta en la sección XI del Canto memorial. El conocimiento de esta lengua le fue ampliando el círculo de amistades que a la vez se interesaban por aprender el castellano y Cabrera fue su maestro. Encontraba con la enseñanza de la lengua de Cervantes un modo de cubrir las necesidades vitales. A las clases se unían como complemento las bien remuneradas traducciones del inglés:

\author{
Por otra parte, varias empresas \\ Mi escaso tiempo solicitaban \\ Para versiones de obras inglesas \\ Que con exceso remuneraban. \\ $Y$ hasta en los bandos y reglamentos \\ Que regulaban actos locales, \\ Iban impresas cual suplementos \\ Mis traducciones como oficiales.
}

En Gibraltar continuó los estudios teológicos, asistía a los cultos y se relacionaba con los ministros del Evangelio españoles y escoceses asentados en la colonia británica: Antonio S. Soler, Pablo Sánchez, Manuel Hernández, Robert Stewart Clough y otros protestantes. Y también aquí comenzó a traducir la citada Exposición histórica y doctrinal de los Treinta y Nueve Artículos del obispo de Ely y luego de Winchester, Edward Harold Browne, cuya primera parte, como he referido, apareció en 1867.

Es este un hecho importante de igual modo que el vínculo más estrecho que estableció con la Iglesia Presbiteriana escocesa. Cuando el presbítero Antonio S. Soler, que tenía a su cargo la Misión española en Gibraltar, tuvo que abandonar la congregación, le encomendó su función a

30 An Extract from the Register of Marriages Kept in this City of Gibraltar in the Year 1863. El certificado matrimonial de Juan Bautista Cabrera y Josefa Latorre (323) fue compulsado en el Consulado británico de Sevilla el 23 de marzo de 1871 por el cónsul M. Williams. El padre Mateos-Gago mantuvo con Cabrera una polémica durante tres años y todavía en 1876, estando ya Cabrera en Madrid, se acuerda de él y sobre todo de su esposa, «la Pepa». Envía una carta al director del ultracatólico periódico El Siglo Futuro, que reproduce el 25 de septiembre de 1876 (2-3). Sigue denigrando al matrimonio como había hecho anteriormente. Le dice al director que forman una «miserable pareja» convertida en importante por «la iglesia cabrerista»: «Vd. Ve: ide un maestro de primeras letras, apóstata y sacrílego, y de una prostituida maestra de lo mismo, han salido el Papa y la gran Papa de la Iglesia Española Reformada...!». (1876: 3. También en 1877: III, 287-293). Josefa Latorre murió el día 11 de marzo de 1923 a los 80 años de edad. 
Cabrera, siguiendo los deseos de la Sociedad de Edimburgo. Era el 13 de noviembre de 1867. A partir de esta fecha, Cabrera empezó a consignar sus actividades en el Diario $\mathrm{G}$, que yo llamo así por pertenecer a la etapa gibraltareña. Llegan sus anotaciones hasta el 29 de septiembre de 1868, en que abandona el enclave. El 13 de noviembre de 1867 el presbítero Cabrera apuntó lo siguiente en esa especie de agenda-diario, que permanece inédita en el archivo de la Iglesia Española Reformada Episcopal (Madrid):

Partió D. Antonio S. Soler para Escocia, y me entregó una carta para que me encargue de la Misión española en la Iglesia Presbiteriana de Gibraltar, según los deseos antes expresados por la Sociedad de Edimburgo, y que me manifestó antes de su muerte Mr. Sutherland, que murió en 18 de octubre anterior.

Desde este día quedé encargado de la Misión, como Agente y Pastor, a las órdenes de la Sociedad de Escocia intitulada Spanish Evangelization Society, Edimburgh. Esperando sin embargo órdenes expresas de esta Sociedad.

De esta manera quedó vinculado formal y activamente a la entidad escocesa: la Free Church of Scotland y la United Presbyterian Church of Scotland. ${ }^{31}$ El encargo de Soler en dicha fecha de 1867 es un momento decisivo porque suponía un cambió en el modo de vivir de Cabrera: dejaba la enseñanza, que había practicado desde su estancia en Gandía y Valencia, y entraba más abiertamente en la senda reformadora que finalmente le llevaría de manera progresiva a ser el primer obispo protestante español y el fundador de la Iglesia Española Reformada.

Un año después, en 1868 , se produjo en ese sentido otro hecho importante, la creación del Consistorio. El 25 de abril de ese año un grupo de seis personas (Cabrera, Pablo Sánchez, Antonio S. Soler, Manuel Hernández, junto con José Alhama y Robert Stewart Clough) se reunieron «en la Sacristía» de la iglesia gibraltareña de Escocia, según anota Cabrera en esa importante fecha de su Diario G, y constituyeron una Junta denominada Consistorio Central, embrión de la que se llamó y se llama Iglesia Española Reformada (y luego Episcopal). El principal objetivo de los seis fundadores del Consistorio era el de propagar la religión reformada en España.

Meses después, el 19 de septiembre de 1868, sucedió la sublevación del almirante Juan Bautista Topete, se pronunciaron los generales Francisco Serrano y Juan Prim y se desencadenó la Revolución Gloriosa. Cabrera, Alhama y Hernández aceptaron la invitación ofrecida por unos amigos (sin especificar) de acudir a Algeciras y en esta ciudad gaditana mantuvieron un encuentro con el general Prim el 23 de septiembre. Escribió en su Diario S2 (o de Sevilla):

Al desembarcar, supimos que venía el general Prim a bordo de la fragata blindada Zaragoza, escoltada por la fragata Villa de Madrid. Algunas horas después, desembarcaba el General. En la recepción que dio, después de admitir a la oficialidad, nos concedió a nosotros una corta entrevista. Yo manifesté al General que todos tres habíamos residido varios años fuera de España, por opiniones religiosas; mis compañeros como desterrados, y yo como emigrado; que aquella noche volvíamos a pisar el suelo patrio, favorecidos por la libertad que principiaba a ponerse en práctica por medio del

\footnotetext{
31 Vilar 1994: 375; Serrano 2000: 537.
}

levantamiento; y que aprovechábamos aquella ocasión para ofrecerle nuestros respetos. Alhama le habló sobre el mismo asunto y concluyó por suplicarle que recordara que hay españoles que profesan otra religión que no es la Católica Romana. El General preguntó: ¿Son ustedes aquellos que fueron condenados en Granada porque se decía que no eran buenos cristianos? Y continuó: Sean ustedes. Bienvenidos. Desde hoy en adelante habrá libertad en nuestra patria, verdadera libertad: ya concluyó la tiranía. Cada hombre será dueño de su conciencia, y podrá profesar la fe que mejor le parezca. Ustedes pueden volver a su país por el primer vapor que salga, y están en libertad de entrar en España con la Biblia bajo el brazo, y predicar las doctrinas en ella contenidas. Estuvo muy afable con nosotros. Le dimos las gracias, y nos retiramos. ${ }^{32}$

FIGURA 3

Diario S2: Encuentro de Cabrera con el general Prim en Algeciras el 23 de septiembre de 1868

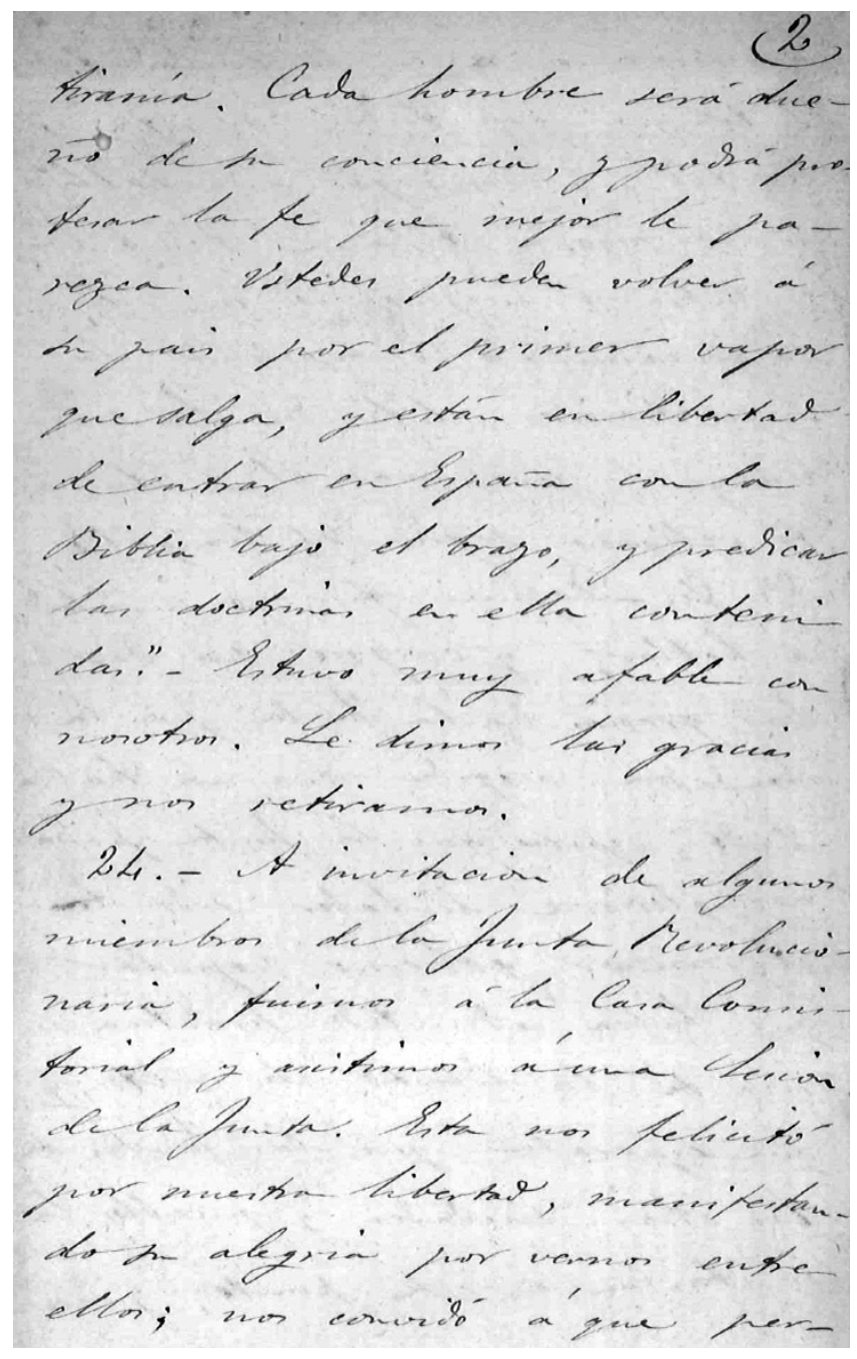

Las palabras de Prim constituyen una adelantada declaración oral de libertad religiosa, libertad que vendría después a consagrar, como vimos, la Constitución de 1869

32 Describe el encuentro aquí con ligerísimas variantes respecto de lo que anota en el Diario G. La versión que reproducimos arriba nos parece más cuidada en la puntuación. También lo refiere en Canto memorial, sección XIV. 
en su artículo 21. El día 24 asiste a la Casa Consistorial en Algeciras por invitación de algunos miembros de la Junta Revolucionaria. Cabrera tomó la palabra y apuntó en la entrada correspondiente de su diario: «Expresé que la Junta se vanagloriase de ser el primer gobierno popular que había admitido prácticamente la libertad de cultos» (Diario S2). Vuelve a Gibraltar y el 29 de septiembre lo abandona de nuevo para dirigirse a Sevilla, adonde llega por primera vez el 1 de octubre a las 10:30 de la noche..$^{33}$

\section{Sevilla (1868-1874)}

La primera estancia de Cabrera en esta capital comprende desde el 1 de octubre al 29 el mismo mes. La actividad reformadora de este breve periodo está recogida en el Diario S2. Viajó hacia Sevilla en compañía de sus "amigos» los políticos Roque Barcia y Cristino Martos. Con ellos compartió también los primeros días en la capital andaluza antes de que ellos emprendiesen viaje a Madrid. Buscó las posibilidades de comenzar su reforma. Celebró el primer culto en una fábrica de fideos el domingo día 4 de octubre y el segundo tuvo lugar el domingo siguiente «en casa de D. Manuel Merino, en medio del patio, al raso, por no ser la sala bastante capaz. La concurrencia fue numerosa» (Diario S2).

Nos consta que el 17 de octubre comenzó las gestiones encaminadas a adquirir un local para capilla. Mantuvo relaciones con personalidades relevantes de la cultura y la política, tales como el doctor Federico Rubio y Galí, del Partido Demócrata, y el profesor Antonio Machado Núñez, perteneciente al Partido Progresista y abuelo de los famosos poetas sevillanos. También hemos constatado que presentó instancias a la Segunda Junta Revolucionaria el citado día 17 y luego al Ayuntamiento el 29 de ese mismo mes de octubre.

En esta última fecha volvió a Gibraltar y emprendió viaje otra vez a Sevilla el día 5 de noviembre siguiente. Llegó el día 6. Aquí residirá desde este día de 1868 hasta que tome posesión de la Iglesia del Redentor de Madrid el 19 de noviembre de 1874 tras la muerte del pastor Antonio Carrasco.

La labor realizada en Sevilla a partir de noviembre de 1868 es destacable en tres puntos principales enfocados a la labor reformadora: la apertura de un templo, la fundación de la revista El Cristianismo (5 de mayo de 1869) y la celebración del primer Sínodo o Asamblea. El primer culto protestante, oficiado ya en un templo de Sevilla, se celebró en el de la calle Las Vírgenes el día 27 de diciembre de 1868 (4 semanas antes que el de Catalina de los Donados, de Madrid). ${ }^{34}$ Luego la congregación se trasladó a la iglesia de

33 En «una rectificación», dirigida a la Revista Cristiana en 1914 y ya citada, afirmaba Cabrera que llegó Sevilla «el mismo día en que se libraba la sangrienta batalla del puente de Alcolea» (35), pero esa batalla se produjo el día 28 y no el 29 de septiembre. Si queremos ser precisos citemos la nota del Diario S2, escrita ese día 29: «[...] me he embarcado a las 5 de la tarde en el vaporcillo Alegría para Cádiz». Desde allí viajaría a Sevilla. Llega el día 1 de octubre. Tal día apunta: «y llegué a las 10 1/2 de la noche».

34 La primera reunión o culto protestante de Madrid tuvo lugar en un salón alquilado en la Plaza de Santa Catalina de los Donados, núm. 2, el día 24 de enero de 1869, por obra de Francisco de Paula Ruet y Antonio Carrasco Palomo. Aquí está el origen de la madrileña Iglesia del Redentor (Cabrera 1907: 254). La misma fecha en el informe que hace el misionero norteamericano William H. Gulick sobre España en 1872 (Gulick 1872: 21). la Santísima Trinidad, es decir, a la llamada San Francisco de Paula, perteneciente antes a los jesuitas.

El seminario, por otra parte, había sido creado con 14 estudiantes en julio de 1869 por la Spanish Evangelization Society, de la que formaba parte la citada señora de Robert Peddie $^{35}$ [Maria Denoon Peddie] y a la que estaba vinculado Cabrera desde Gibraltar. Aquí es donde nace, con Carlos Araujo Carretero en primer lugar, la saga Araujo de pastores protestantes.

La celebración del Primer Sínodo o Asamblea en Sevilla, presidido por Cabrera, da continuidad al Consistorio de Gibraltar, constituido en abril de 1868. Según Serrano ${ }^{36}$ y García Rubio, comenzó "el día 26 de julio» y "concluyó el 16 de agosto» de 1869. La convocatoria iba firmada por Cabrera y Luis A. Fernández ${ }^{37}$ el 27 de junio. ${ }^{38}$ Es importante este sínodo por la gran relevancia que los acuerdos tomados adquieren en la historia del protestantismo español desde dos puntos de vista. Internamente: por aprobar una Confesión de Fe, hacer un Himnario, un Catecismo, elaborar un código de Disciplina... y adoptar de manera oficial la Biblia vertida al castellano por Casiodoro de Reina en 1569, revisada por Cipriano de Valera en 1602.

Externamente, se envió la Confesión de Fe a las Cortes y éstas respondieron a la recepción. Destaca Gutiérrez Marín, perteneciente a la Iglesia Evangélica Española, la importancia que suponía la respuesta de las Cortes porque con ella se otorgaba carta de naturaleza «para que la Iglesia Protestante saliera de su clandestinidad y pudiera, sin temor a represalias gubernamentales, ejercer su función evangelizadora entre el pueblo». ${ }^{39}$

La Asamblea concluyó el 16 de agosto y el presidente Cabrera pronunció unas palabras que el presbítero Serrano reproduce con amplitud. ${ }^{40}$ Constituyen una muestra del espíritu edificante que movía su actuación como presidente y como reformador. Dijo entre otras cosas:

Recuerdo que el año pasado, para la formación del Consistorio anterior, sólo nos reunimos seis personas; hoy nuestro número ha sido triplicado. ¿Quién sabe cuántos seremos para la Asamblea del año próximo?... Nuestra milicia es espiritual, y no carnal. Peleamos por la causa de Dios, y es menester por lo tanto que nos preparemos para el combate [...]. Yo os recomiendo a vosotros, Ministros, a vosotros, Evangelistas, y a todos en general, la humildad y la caridad. Sed piadosos en vuestras palabras, en vuestras predicaciones. Inducíos unos a otros en la perfección. Seamos modelos de todos nuestros hermanos [...]. Prediquemos, instruyamos, extendamos la Iglesia de Dios sin temor y sin descanso, no por espíritu de partido, sino por fe. Salgan de nuestros labios las palabras del Evangelio revestidas de amor cristiano, de manera que nuestros enemigos no las rechacen. [...]. Hoy, hermanos míos, reina en nuestra patria la indiferencia más completa; hoy se habla de religión solamente para mancillarla; hoy el manto de

35 Peddie 1871.

36 Serrano 2000: 545.

37 García Rubio 1994: 186-191.

38 Gutiérrez Marín dice que tuvo lugar el 15 de julio (1942: 262); y Wylie apunta que comenzó el 5 de ese mes (1870: 302). En ambos casos parece ser errata de 25. Según García Rubio, la reunión comenzó el 26 (1994: 189).

39 Gutiérrez Marín 1942: 263.

40 Serrano 2000: 545-547. 
la hipocresía cubre generalmente nuestro sociedad. Y es que se han cuidado mucho de las formas y poco del fondo [...]. Nosotros hemos de ser todo lo contrario: hemos de predicar la fe y no el fanatismo; hemos de predicar el amor y no la parcialidad; hemos, finalmente, de contribuir a la regeneración espiritual de los hombres para que muera en ellos el viejo Adán [...]. ${ }^{41}$

Sentidas palabras que muestran de su emisor la capacidad para la edificación espiritual. Apuntaba también a la celebración de la segunda Asamblea en el año siguiente. Pero la reunión prevista no iba a tener lugar hasta el 11 de abril de 1871.

Conocía también Cabrera la existencia de cierto radicalismo antiprotestante. No tardaría en comprobarse este fenómeno de intransigencia, pues este primer Sínodo dio motivo al padre Cayetano Fernández, chantre de la catedral de Sevilla, para componer "Los cánones caprinos», poesía denigratoria contra Cabrera y su obra publicada con una introducción en El Oriente de Sevilla el 22 de agosto de 1869 , diez días después de clausurada la Asamblea. MateosGago reproduce en el volumen III de sus Opúsculos ${ }^{42}$ el conjunto de cincuenta y ocho pareados endecasílabos en los que el autor pretende presentar "todo lo concerniente a personas, dogmas, oficios, etc.» de la iglesia y el credo de Cabrera. El chantre sevillano pinta a los protestantes como seres de baja condición moral e intelectual. Su Biblia, por prescindir de los libros apócrifos, es incompleta. Para el padre Cayetano, los sacramentos no reconocidos como tales y otros puntos de doctrina divergentes, así como los aspectos litúrgicos propios del protestantismo, hacen del cabrerismo no una creencia, sino una religión demencial. ${ }^{43}$

La segunda Asamblea sevillana se celebró entre el 11 y el 20 de abril de 1871. Tuvo lugar en la iglesia de San Francisco de Paula, ahora propiedad de los protestantes a la que denominaron iglesia de la Santísima Trinidad. ${ }^{44}$ Esta Asamblea perseguía el objetivo de crear las bases para fundar la Iglesia Cristiana Española (ICE). Cabrera deseó la «Unión Evangélica de todas las iglesias de España», según consta en el acta de la primera sesión levantada al efecto y firmada por el secretario L. Moulet y por el presidente Celedonio Martínez. Las 13 iglesias asistentes, pertenecientes a las agrupaciones de la Iglesia Española Reformada y la Iglesia Evangélica Española, adoptan el nombre de Iglesia Cristiana Española.

En las Asambleas de los años 1872 y siguientes, celebradas en Madrid o en Sevilla, van acentuándose las desavenencias entre los españoles y extranjeros concurrentes. Sobre todo en la sevillana de 1874, moderada por Cabrera. A partir de entonces se acelera la ruptura y llegará el divorcio formal.

La Asamblea de 1876 fue también muy controvertida debido entre otras cosas a la discusión acerca del Código de disciplina y la forma organizativa, presbiteriana o no, de la ICE.

41 Ibídem: 546.

42 Mateos-Gago 1877: III, 160-168.

43 Me ocupé en otro trabajo de ésta y otras poesías contra Cabrera (Ríos Sánchez 1995). Evito insistir. Sólo transcribo como muestra el 5 o canon: «V. Para ser simple cabra es suficiente/ El ser tonto, menguado e inconsciente».

44 El consejero de la Nunciatura de Madrid, Mariano Rampolla, envió un despacho al cardenal Antonelli, secretario de Estado, el 6 de agosto de 1875 sobre el estado del protestantismo en España y decía que «la chiesa di san Francesco di Paola é situata in una delle migliore strade di Siviglia, ove prima della revoluzione i padri Gesuiti facevano moltissimo bene» (Cárcel Ortí 1984: 119).
Una minoría (4 de 7) se oponía al sistema presbiteriano, ya que si tuviera ese carácter algunos de los obreros extranjeros que trabajaban en España no querrían integrarse en ella. Entre los que formaban parte de la minoría, opuesta a la organización presbiteriana de la ICE y al discutido Código de Disciplina, se encontraba el pastor alemán Federico Fliedner y el misionero escocés John Jameson. ${ }^{45}$

Se programó otra Asamblea para 1877 en Granada, pero hubo de suspenderse por escasez de asistentes. La celebrada en Madrid al año siguiente tuvo escasa trascendencia, aunque por el tema y la figura que nos ocupa hemos de señalar que en ella se aceptó el Himnario para uso de la Iglesia Cristiana Española (1878) que Cabrera acababa de publicar con más de 300 himnos.

Y en la Asamblea de Madrid de mayo de 1880 Cabrera ya no estuvo presente porque, según Serrano, «antes de dicho mes ya había tenido lugar, en Sevilla, la constitución de la Iglesia Española, independiente de la Iglesia Cristiana Española». ${ }^{46}$ Las iglesias que no siguieron a Cabrera continuaron llamándose así hasta 1886 en que aglutinadas en torno a Fliedner dan lugar a la Iglesia Evangélica Española.

Para concluir este apartado, anotaré que, según el informe del reverendo H. Duncan, en torno a 1877-1878 el número de asistentes a los cultos reformados en España en las 12 [sic] congregaciones ${ }^{47}$ que desde abril de 1871 y hasta 1878 constituyeron la alianza de denominaciones conocida como Iglesia Cristiana Española oscila entre 2.500 y 3.000.48

\section{Madrid (19 de noviembre de 1874-18 de mayo de 1916)}

La muerte del pastor Antonio Carrasco Palomo en 1873 quiebra la estancia de Cabrera en Sevilla. Carrasco, fundador de la Iglesia del Redentor de Madrid y del periódico La Luz, volvía de Nueva York en el barco Ville du Havre que naufragó en la madrugada del 21 al 22 de noviembre de dicho año. Había participado en la conferencia general de la Alianza Evangélica celebrada en Nueva York entre el 2 y el 12 de octubre de 1873. Cabrera entonces aceptará el cargo de rector de la Iglesia del Redentor de Madera Baja, vacante por la muerte de Carrasco.

El alejamiento de Cabrera respecto del Comité de Escocia, cuya vinculación formal se estableció el 13 de noviembre de 1867, ya es formalmente detectable en 1878 cuando busca lazos con la Iglesia de Inglaterra. En julio de ese año se celebró la Conferencia de Lambeth. ${ }^{49}$ Entonces el arzobispo de Dublín, lord Plunket, conoció la solicitud efectuada por Cabrera en tal sentido. Plunket dejaba constancia del hecho en la introducción al libro del reverendo H. E. Noyes (1897). Manifestaba que en aquel año de 1878 supo de «a formal request had been submitted to that Conference from a body of Reformers in Spain and Portugal praying for the consecration of a Bishop». ${ }^{50}$

45 García Rubio 1994: 316-317.

46 Serrano 2000: 582.

47 Duncan 1877: 308.

48 Ibídem: 308.

49 Noyes 1897: 57.

50 Ibídem: X. Frederick Meyrick (1827-1906) confirma tal petición de fraternal reconocimiento solicitada por Cabrera en 1878 y la aceptación y apoyo que manifiesta lord Plunket desde que conoce esta solicitud hasta la consagración de Cabrera (Meyrick 1905: 231, 316). 
El 15 de julio de 1879 , se celebra una Junta de la Congregación de la Iglesia del Redentor. Según el acta de la misma, Cabrera expone en ella las vicisitudes por las que pasa la Iglesia desde el año anterior. Ante la imposibilidad de mantenerse en el cargo de pastor por la falta de recursos del Comité escocés que le sostenía, «resolvió con la autorización de la Junta marchar a Londres a fin de gestionar personalmente su colocación por cuenta de otro Comité o de la forma que fuera más aceptable sin lastimar la dignidad de su iglesia». ${ }^{51}$ Sólo encontró apoyo económico en la Sociedad conocida como Misiones Eclesiásticas de España y Portugal.

Y el 2 de marzo de 1880 funda la Iglesia Española Reformada de orientación episcopal en el Sínodo celebrado en Sevilla. Estuvo presidido por Riley, obispo de México, y en él Cabrera es elegido obispo. ${ }^{52}$ Este Sínodo ratificaba el acuerdo de la Junta del 24 de febrero de 1880 de la congregación del Redentor con cargos y organización nuevos. En el sínodo de 1883 se consolida la Iglesia Española a la que se añade ahora el adjetivo Reformada. Se adoptan 38 de los 39 artículos de la Iglesia Anglicana (suprime el 35 por referirse a las homilías que manda leer esa Iglesia) y se adoptan las Bases de Disciplina, el Catecismo y un Himnario.

Gran relevancia adquiere para la nueva Iglesia la erección y consagración del tempo de la calle Beneficencia de Madrid (1891-1892). Las condiciones físicas del edificio de Madera Baja eran muy poco confortables y con la ayuda del obispo irlandés W. Conyngham Plunket se consiguen fondos para la erección del nuevo templo y las escuelas adyacentes. La primera piedra se coloca el 19 de marzo de 1891.

Estaba prevista su consagración para el 1 de diciembre de 1892, pero por orden del alcalde de Madrid, el conde de Peñalver, se impidió su apertura porque ostentaba una cruz en su fachada con la leyenda Christus Redemptor Aeternus. Se consideraba signo de culto disidente. La apertura hubo de retrasarse hasta el 17 de marzo de 1893 y la consagración tuvo lugar el 23 de septiembre de 1894, al mismo tiempo que Plunket transmitió el orden episcopal a Cabrera.

La revista La Luz (XXVI, núm. 694) del 30 de septiembre de 1894 contiene información de mucho interés y de primera mano por ser el órgano de la Iglesia Española Reformada. Cabe destacar los siguientes artículos: "Acta de consagración del obispo don Juan B. Cabrera»" "La consagración del señor Cabrera», firmado por P. [edro] S. [ala] ${ }^{54} \mathrm{y}$ "El asunto del día», sin firma. ${ }^{55}$ En éste se lee:

Antes de inaugurar nuestro Templo en Madrid tuvimos que quitar la Cruz de su fachada, por disposición del Alcalde, fundada en la Circular del Sr. Cánovas mal interpretada, pues jamás se ha definido que la Cruz sea símbolo de un culto disidente. En este mismo año, por orden verbal del Gobernador, hubimos de cerrar la puerta exterior de nuestro Templo, sin reparar en el absurdo de que se pretenda que utilicemos un edificio sin puerta. ${ }^{56}$

La puerta principal permaneció cerrada durante los 11 años siguientes a su inauguración en 1893, pues no se pudo

51 Citado por Serrano 2000: 218.

52 Noyes 1897: 9 y 62-63; Mayor 1892: 31.

53 Anónimo 1894: 210-211.

54 Ibídem: 211-212.

55 Ibídem: 212-214.

56 Ibídem: 213. abrir hasta el 28 de mayo de 1905, según anotó Cabrera tal día en su Memorándum. Y en cuanto a los polémicos signos externos, Serrano señala que «hasta el 3 de agosto de 1910 no pudo ser repuesta en la fachada la cruz gótica que había sido mandada retirar por el Ayuntamiento 17 años antes». ${ }^{57}$ La inscripción Christus Redemptor Aeternus nunca se restituyó. ${ }^{58}$

En el trabajo de $\mathrm{How}^{59}$ y en el de Noyes, que estuvo presente en la solemnización del acto $^{60}$, se reproduce la descripción de la ceremonia que apareció en la revista Light and Truth. Se dice, entre otros detalles, que leyó la Epístola el obispo de Clogher (C. M. Stack) y que al obispo de Down (C. Welland) le correspondió la lectura del Evangelio. Por su parte, Francisco Palomares, «el más antiguo pastor de la Iglesia Española Reformada», tuvo a su cargo la predicación basada en el versículo "Yo soy la luz del mundo» (Jn 8, 12). Al arzobispo Plunket le cupo en la ceremonia la transmisión del orden episcopal. ${ }^{61}$

Figura 4

Fragmento del acta de transmisión del Orden episcopal por el arzobispo Plunket en 1894

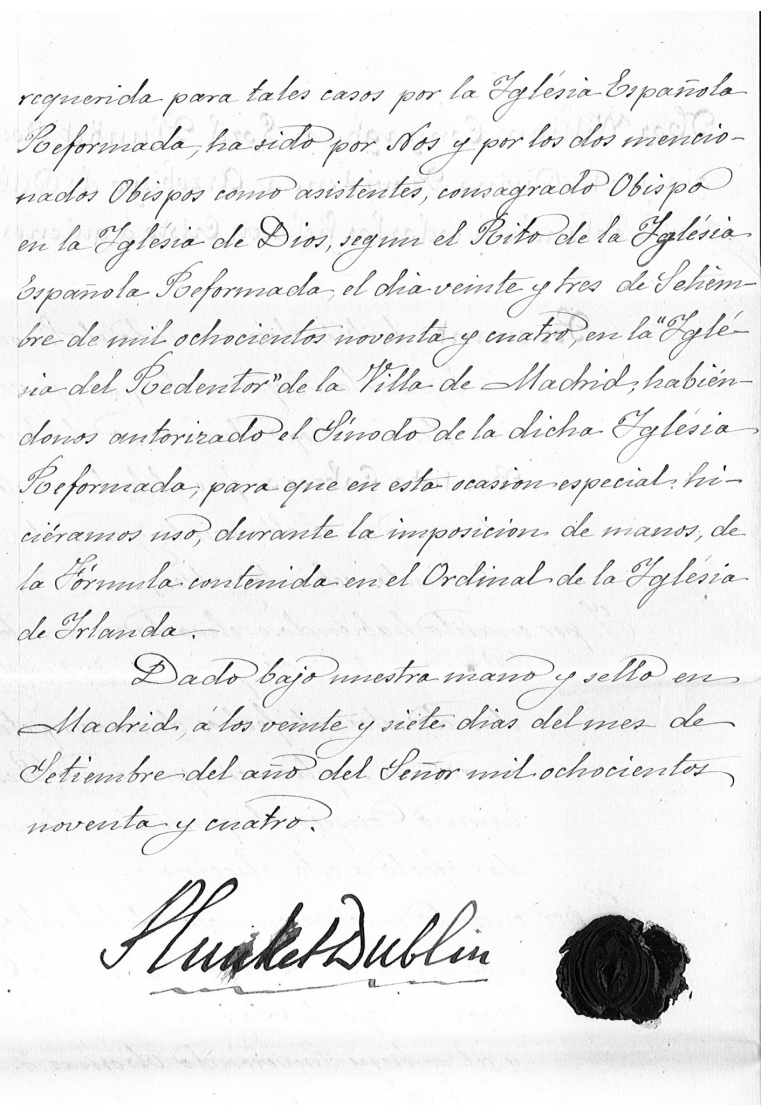

57 Serrano 2000: 304-305

58 Una descripción detallada de la arquitectura, fachada, estilo y dimensiones internas del templo se halla en «La Iglesia Evangélica del Redentor de Madrid», artículo sin firma publicado en La Luz, XXVI, núm. 681, 15 de marzo de 1894 (Anónimo 1894: 55-58).

59 How 1900: 272-281.

60 Noyes 1897: 91-93.

61 El periódico ultracatólico El Siglo Futuro del 19 de octubre de 1894 reproduce la relación de la consagración del templo y del obispo por lord Plunket en The Times. Para el periódico español, la ceremonia fue una «mojiganga» y una «parodia» ([Plunket] 1894: 2-3). 
La apertura y consagración del templo y del obispo Cabrera produjo reacciones en distintos ámbitos, desde los devotos más humildes hasta las más altas jerarquías. Benisa, su villa natal, se mostró expresamente contraria a la apertura del templo madrileño en una protesta del 17 de enero de 1893 publicada al efecto y bajo el título "Benisa y la capilla luterana» en La Unión Católica. Diario Religioso, Político y Literario el 21 de enero de dicho año. Entre otras cosas manifestaban los firmantes: "la villa de Benisa, hondamente afectada por la circunstancia de ser hijo suyo el expadre Cabrera, protesta enérgicamente ante tal deshonra y le declara hijo expúreo [sic y cursiva suya], ya que contrasta su cínico proceder con el de todos los demás, que son católicos, apostólicos, romanos sin ningún género de reformas» (1). Y Cristóbal Robles Muñoz ${ }^{62}$ ha estudiado con atención las registradas en el ámbito político y eclesiástico. Yo me ocupé de los poemas satíricos contra Cabrera. ${ }^{63}$

Por la relevancia del autor, quiero recordar que Leopoldo Alas Clarín publicó en el semanario Madrid Cómico (4 de febrero de 1893: 3 y 6), es decir, unas semanas antes de la inauguración del templo el 17 de marzo, el palique Diálogo edificante. Con su espíritu crítico y moralista, denunciaba el escritor asturiano la incoherencia de quienes se oponían a la apertura de una capilla evangélica en Madrid al tiempo que mantenían inacabada la basílica de Covadonga. ${ }^{64}$ Al año siguiente de su publicación, Clarín lo recogió con otros escritos periodísticos diversos en Palique y en 1917 Martínez Ruiz Azorín ${ }^{65}$ lo seleccionó en Páginas escogidas del autor asturiano, a quien define en el prólogo como un hombre de "espiritualismo laico» y "más sentimental que de la razón». ${ }^{66}$

\section{AMISTADES Y DISTINCIONES. MIEMBRO DE LA HISPANIC SOCIETY OF AMERICA}

El citado periodista Bernat Capó le ha relacionado con Gustavo Adolfo Bécquer, con José Zorrilla y con Emilio Castelar. Yo no he encontrado el testimonio que acredite esta relación. Ello no quiero decir que lo niegue. De lo que no cabe dudar es de que Cabrera se relacionó con los políticos Roque Barcia y Cristino Martos, con el doctor Federico Rubio y Galí, como hemos dicho, y con el poeta valenciano Vicente Wenceslao Querol. ${ }^{67}$ Muy estrecha fue la conexión con el político Práxedes Mateo Sagasta. Y alcanza relevancia el nombramiento honroso de Cabrera como miembro de la Hispanic Society of America en 1915.

La relación con el progresista Sagasta se establece dentro del marco de la masonería. No es nada nuevo decir ahora que Cabrera fue masón. También lo fueron otros muchos pastores protestantes y muchas personalidades de la política y de otros campos de la actividad artística y literaria.

\footnotetext{
62 Robles Muñoz 2001.

63 Ríos Sánchez 1995.

64 Ibídem 1998.

65 Martínez Ruiz 1917.

66 Ibídem: 18.
}

67 Cabrera dedicó el poema «Vida y muerte» a Querol y reproduce una carta-respuesta de éste en Poesías religiosas y morales (Cabrera 1904: 268-271).
Algunas publicaciones periódicas de finales del siglo XIX aludían, tendenciosamente, a la vinculación de Cabrera con esta asociación. Por ejemplo, El Siglo Futuro del 4 de diciembre de 1894 inserta un artículo titulado "Historia masónica del seudo Obispo Ex-padre Cabrera». Lo toma de La Semana Católica. Se destaca en el escrito la influencia que Cabrera tuvo en 1876 para elegir a Sagasta como Gran Maestre y Gran Comendador del Gran Oriente de España, en cuya logia Mantuana figuraba Cabrera con el grado 30. Por entonces se había producido una crisis en el seno de la Gran Logia que se trató de resolver con la elección de Sagasta. Dice el diario ultracatólico que en los trabajos de reorganización tomó parte Cabrera como orador ${ }^{68}$ :

En Abril juró su cargo el Sr. Sagasta, y en el mes de Agosto del mismo año (1876), el Gran Oriente publicó un curioso documento haciendo la historia de esta elección, documento que, entre otras firmas, lleva la de Juan B. Cabrera, como orador del Soberano Capítulo y de la Gran Logia.

Resulta, pues, que, desquiciada la masonería, se reorganizó por el prestigio de Sagasta, y que en estos trabajos de reorganización tomó parte principalísima Cabrera. (1)

Claro debe quedar el hecho de que para el tendencioso diario toda esta actividad de Cabrera perseguía un fin muy personal: puesto que Cabrera «necesitaba adeptos» para su nueva iglesia, consideró que "entre los masones podía encontrarlos. Y así fue, y de aquí salió el primitivo núcleo de su mal llamada iglesia» (1).

Como afirma El Siglo Futuro, Cabrera tomó parte importante en la reorganización y el aupamiento de Sagasta. De manera que no es cierto que Cabrera «fue iniciado en los misterios de la Masonería en 1888, en la R. Logia Mantuana, no 1», como afirmaba Guillermo Oncins en 1996. ${ }^{69}$ La iniciación masónica de Cabrera se remonta varios años atrás. Para la corrección o matización de esos detalles de cronología y pertenencia masónica de Cabrera me baso en dos documentos fidedignos que se conservan en el archivo personal de Rosario Morales Cabrera. Uno de ellos relativo a la concesión del grado 30 («Caballero Kadosch») que le fue otorgado en 1876. Junto al título se conserva el resguardo que acredita haber:

Recibido del $\mathrm{H}$ :. Juan Bautista Cabrera las med:. prof:. de veinticinco pesetas por el título del gr:. 30, más tres pesetas por su registro en tal Gr:. Cám:. de Ritos; como Gr:. Tesor:. del S:. J.. del Ser:. Gr:. Or.: de España. Madrid 2 de Octubre 1876 (e:. v:.).

Lo firma el tesorero Juan Francisco de Novales en Madrid el 2 de octubre de 1876. El otro documento masónico corresponde al título del grado 33 que le fue concedido en 1884. Le acompaña también el recibo de haber satisfecho un importe semejante para su obtención el 2 de abril de 1884. Lleva sello de la Tesorería y lo firma, en este caso, el tesorero Justo Jiménez.

68 Gonzalo Sanz y Carlos Mayor definen así al orador: «Oficial de la logia que vela por el cumplimiento de las normas constitucionales y del reglamento, así como, en líneas generales, el cumplimiento de los principios fundacionales y tradicionales de la masonería. Tiene palabra y puede incluso interrumpir al Venerable Maestro» (Sanz y Mayor 2006: 236).

69 Oncins 1996. 


\section{FIGURA 5 \\ Recibo de la obtención del grado 30 en el Gran Oriente de España}

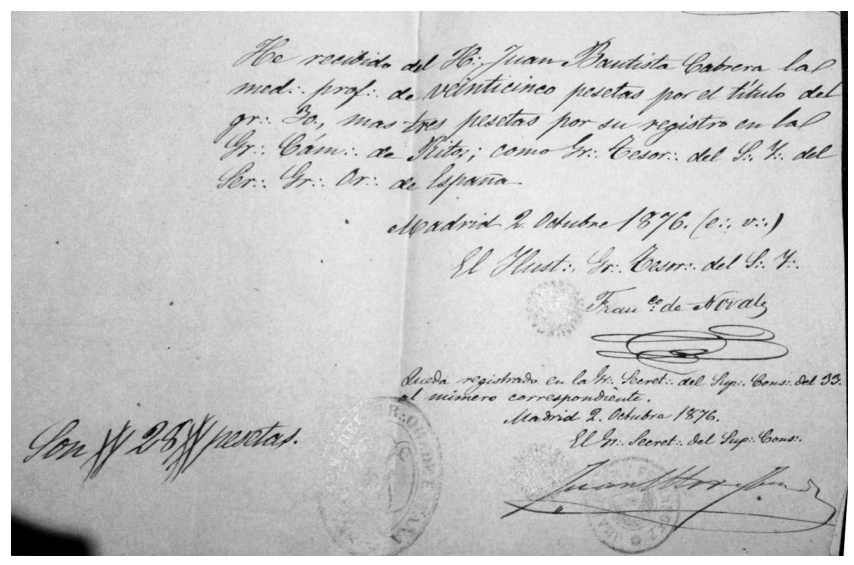

De otro lado, los profesores Andrew Prescott y Sylvia Hottinger son autores de un trabajo fundamental publicado en 2006 en el que demuestran la mediación de Cabrera para buscar vínculos entre el Gran Oriente de España, es decir, de Sagasta, y la Gran Logia Unida de Inglaterra. Al trabajo de Prescott y Hottinger remitimos al lector. ${ }^{70}$ Baste decir ahora que esos investigadores reproducen en facsímil y transcriben mecanográficamente la carta que, fechada en Madrid el 14 de mayo de 1879 y firmada por Sagasta como Gran Maestre y por Juan Utor Fernández como Gran Secretario General, va a entregar personalmente Cabrera a John Hervey, Gran Secretario de la Gran Logia Unida de Inglaterra. ${ }^{71}$

Importancia fundamental adquiere el nombramiento que a Cabrera otorga la Hispanic Society of America como miembro de esta prestigiosa institución neoyorquina. Constituida en 1904 con el fin de fomentar el Arte y las Letras de España, Portugal e Hispanoamérica, abrió sus puertas el 20 de enero de 1908. Cuenta su fundador Archer M. Huntington en una carta a su madre que quería que la institución condensase «el alma de España». Mitchell A. Codding, director de la institución, transcribe un fragmento de la carta en «El alma de España en un museo». Por él vemos el concepto de museo de la cultura española que pretendía Huntington:

Mi afán de coleccionar ha tenido siempre -como tú bien sabes - un trasfondo: un museo. Un museo que ha de abarcar las bellas artes, las artes decorativas y las letras. Ha de condensar el alma de España en contenidos, a través de obras de la mano y del espíritu. No ha de ser un montón de objetos acumulados al buen tuntún hasta que todo ello parezca una asamblea artística - los vestigios

70 Prescott y Hottinger 2006. Y también al libro Juan Bautista Cabrera Ivars. Introducción a la vida y obras de un reformador español del siglo XIX, del que soy autor y que en breve espacio de tiempo publicará la editorial Juan de Valdés.

71 Dos días después de la fecha de la carta, Cabrera emprendía el viaje. El 16 de mayo de 1879 asienta esta nota en el primer cuaderno del Memorándum: «Salí para Inglaterra, quedando en mi lugar D. José Aguilera, encargado de la predicación. Regresé el 5 de Julio» (34). Este viaje no lo emprendió exclusivamente con este fin, pues, como dije arriba, diez días después de la vuelta Cabrera tuvo reunión general con la comunidad de la Iglesia «para manifestarle mi nueva posición como Pastor sostenido por la sociedad Spanish and Portuguese Church Missions». Se daba así un paso más en la senda del episcopalismo. medio muertos de naciones entregadas a una orgía-. Lo que quiero es ofrecer el compendio de una raza, una serie de exposiciones fidedignas, y un grupo de administradores bien formados. Y auténtica investigación.

Declaraba en el párrafo siguiente que quería «conocer España como es, y dejarla reflejada en un museo». ${ }^{72}$ Y así es. Viajó por España y las salas del museo contienen diversas formas de la creación que salen de la mano del hombre o brotan de su espíritu en una amplia variedad de aspectos. En ese museo-biblioteca se custodian colecciones importantísimas de artes plásticas: pintores españoles como El Greco, Zurbarán, Velázquez, Murillo, Zuloaga, Fotuny, Beruete..., y sobre todo Joaquín Sorolla. Alberga también una rica representación bibliográfica y de manuscritos, piezas de cerámica, fotografías, etc.

Del tesoro condensado en la Hispanic Society habla Federico de Onís en términos muy elogiosos. Este profesor español en la Universidad de Puerto Rico comenzó su relación con Huntington en 1916 cuando obedeciendo a su propuesta fue a Estados Unidos. Trabajó en la Sociedad durante algún tiempo y según Onís, la biblioteca y el museo de la Hispanic Society:

Constituyen el monumento más grandioso que se ha levantado a España en el extranjero. La inteligencia, el amor y la devoción de un solo hombre, Archer M. Huntington, nombre que debe sonar siempre en labios españoles con gratitud y admiración, han hecho el milagro de reconstruir en esta ciudad de Nueva York una síntesis espléndida de lo más alto de nuestra civilización, que estará aquí ante los ojos de los norteamericanos como una enseñanza perpetua de lo que nuestro espíritu es y de lo que hemos hecho por el mundo. ${ }^{73}$

Por su parte, José García-Mazas nos informa del tipo de miembros elegidos por la Sociedad:

Desde 1904, los directores de la Sociedad Hispánica de América han elegido miembros de esta sociedad a eruditos, por sus grandes realizaciones en los campos de las letras y las artes hispánicas. Los miembros están limitados a un centenar solamente, y se extraen del grupo de «miembros correspondientes», los cuales no han de pasar de trescientos. ${ }^{74}$

En otro párrafo detalla los dos tipos de medalla de membresía, de plata o de bronce, que la Sociedad otorgaba a los elegidos:

Para honrar a los miembros recién nombrados, la Sociedad instituyó la «Medalla de los Miembros», en plata para los Miembros, y en bronce para los Miembros Correspondientes. Fue diseñada esta medalla por Emil Fuchs, siendo concedida por primera vez en noviembre de 1906, y desde entonces hasta $1924 .^{75}$

72 Codding 2000: 28.

73 Onís 1957: 22.

74 García-Mazas 1962: 423.

75 Ibídem: 423. García-Mazas traduce el apartado III (ibídem: 38-41) de A History of the Hispanic Society of America. Museum and Library. 1904-1954, obra realizada por los miembros del Staff (1954). Existían medallas de modalidades distintas: Medalla de Artes y Literatura, Medalla de Sorolla, Medalla de Cervantes, etc. Recibieron la medalla de Artes y Literatura distinguidas personalidades de esos campos creativos hispánicos. Por lo que se refiere a España, Ignacio Zuloaga (1910), Vicente Blasco Ibáñez (1911), José Echegaray (1913), Ramón Menéndez Pidal (1913), Emilia Pardo Bazán (1913), el marqués de Vega Inclán (1913), Enrique Granados (1916), Benito Pérez Galdós (1919), Miguel 
FIGURA 6

Diploma expedido por la H. S. of A. Cortesía de Rosario Morales Cabrera

\section{THE HISPANIC SOCIETY OF AMERICA}

TAKES PLEASURE IN NOTIFYING

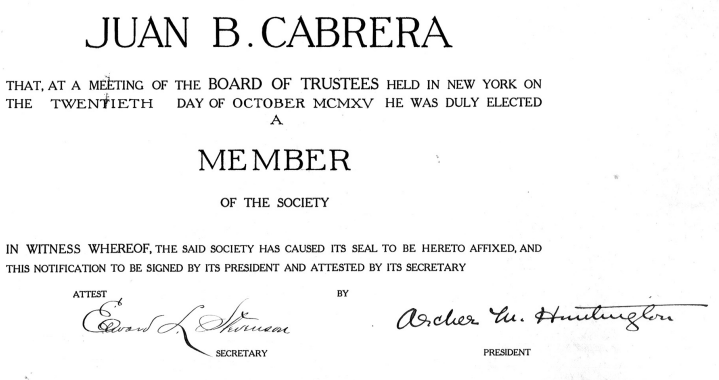

En la biblioteca-archivo de Rosario Morales Cabrera, bisnieta de Juan Bautista, he podido observar la Medalla de Miembros, acuñada en plata, de 7,6 cm. de diámetro, que le fue enviada por la Hispanic Society. Y también el diploma acreditativo con ocasión del nombramiento, firmado por el presidente, Archer M. Huntington, y certificado por su secretario, Edward Luther Stevenson, que lo fue entre 1910 y 1915. La Medalla muestra en el anverso a dos musas de las artes que se apoyan sobre un ara con el logotipo de la Hispanic Society y la leyenda The Hispanic Society of America. El reverso representa una alegoría de Nueva York que tutela a un joven mientras le muestra el globo terráqueo.

FIGURA 7

Medalla de Miembros otorgada a Cabrera en 1915. Cortesía de Rosario Morales Cabrera

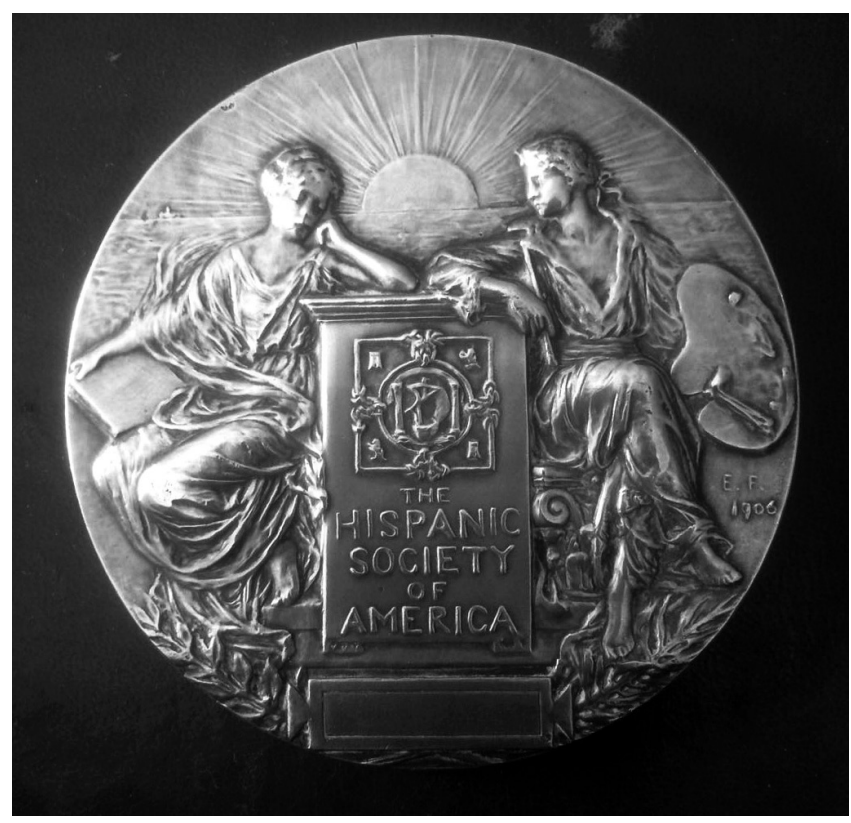

de Unamuno (1919) y Concha Espina (1927). Años después: Manuel de Falla (1945), Juan Ramón Jiménez (1949), José Ortega y Gasset (1949), Fco J. Sánchez Cantón y Diego Angulo (1952), Gregorio Marañón (1952) y algunos más. Entre los escritores hispanoamericanos, el nicaragüense Rubén Darío (en el mismo año en que Cabrera, 1915) o la chilena Gabriela Mistral (1945).
El nombramiento y acreditación junto con el sello de la Sociedad le fueron otorgados a Cabrera el 20 de octubre de 1915, pero sorprendentemente no dejó anotado nada en ninguno de los dos cuadernos de su Memorándum. Se le comunicaba la designación así:

The Hispanic Society of America take pleasure in notifying Juan B. Cabrera that, at a meeting of the board of trustees held in New York on the twentieth day of October MCMXV he was duly elected a member of the Society.

In witness thereof, the said society has caused its seal to be hereto affixed, and this notification to be signed by its president and attested by its secretary.

$\begin{array}{ll}\quad \text { Attest by } & \\ \text { Secretary } & \text { President } \\ \text { Edward L. Stevenson } & \text { Archer M. Huntington }{ }^{76}\end{array}$

No se especifican en él las razones de su elección, pero Huntington y la dirección de la Sociedad por él fundada sabían que el protestantismo, aunque minoritario en nuestro país, ha sido parte del "alma de España» a la que se refería su fundador; y Cabrera, durante la Segunda Reforma, fue el protestante más relevante. En él y en su obra reformadora se compendiaba ese periodo. Vilar, catedrático de Historia Moderna y Contemporánea de la Universidad de Murcia, ha dejado en Intolerancia y libertad en la España contemporánea (1994) esta estimación acerca de la contribución de Cabrera a la historia del protestantismo en el periodo de la llamada Segunda Reforma. Después de examinar su compleja tarea fundadora y su obra escrita hacía esta particular apreciación:

Todo este vasto entramado no hubiera sido posible sin el formidable esfuerzo personal de Cabrera, humanista al viejo estilo, hombre de conocimientos y curiosidad universales, fino observador y de exquisita sensibilidad. Pero, sobre todo, un genio para la liturgia como lo fuera en su momento Thomas Cranmer, y como éste injustamente perseguido y cruelmente denostado. ${ }^{77}$

Unas líneas después y basado en la contribución al amplio campo en que Cabrera desarrolló su obra (teológica, litúrgica, pastoral, organizativa, de investigación, traducción y estudio) continuaba la etopeya con estas otras palabras: «Sin duda, por ello, y con escaso riesgo de exagerar, pueda considerarse al ex-escolapio alicantino como principal arquitecto de la II Reforma en España». ${ }^{78} \mathrm{Y}$ sin dejar de reconocer que existe en Cabrera alguna tendencia personalista, «explicable en cierta medida en quien estaba tan excepcionalmente dotado como organizador", subraya el profesor Vilar entre sus cualidades envidiables "una integridad por encima de toda sospecha y una mansedumbre verdaderamente cristiana que le permitía afrontar con firmeza los mayores infortunios». ${ }^{79}$

76 «La Hispanic Society of America tiene el placer de notificar a Juan B. Cabrera que en la reunión que el comité de dirección ha mantenido en Nueva York el día veinte de octubre de MCMXV ha sido debidamente elegido miembro de la Sociedad. Deja constancia de este hecho mediante el sello adjunto a esta notificación, firmada por el presidente [Archer M. Huntington] y certificada por el secretario [Edward L. D. Stevenson]».

77 Vilar 1994: 381.

78 Ídem.

79 Ibídem: 382. 


\section{APÉNDICE 1. ObRA ESCRITA DE JUAN BAUTISTA CABRERA}

Obra en prosa

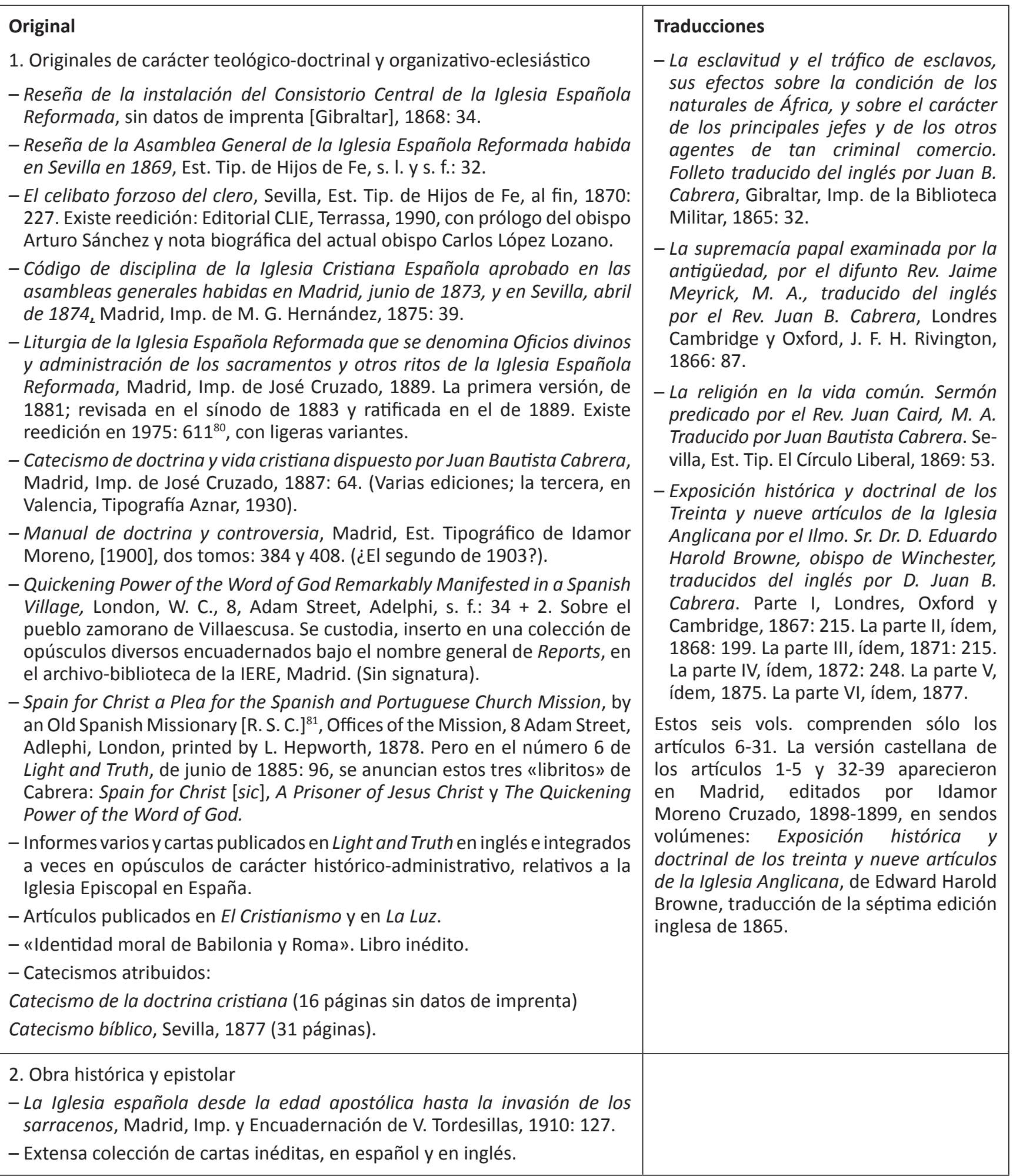

${ }^{80}$ En el vol. II, número 11 de Light and Truth, noviembre de 1881, se reproduce una crítica de Oficios divinos y administración de los sacramentos y otras ordenanzas en la Iglesia Española, Madrid, 1881. La crítica se titula "The Spanish Liturgy» (179-181). No lleva firma, y procede de Foreing Church Chronicle and Review. En el vol. III, número 3 de la misma revista, marzo de 1882, se reproduce otra crítica con este título: "Introduction to the Liturgy of the Spanish Church», por el obispo de Meath (Plunket): 35-40. Se continúa en el número 4, abril de 1882: 51-55.

${ }^{81}$ R. S. C. son las iniciales de Robert Stewart Clough, presbítero que formó farte con Cabrera y otros en la constitución del Consistorio en Gibraltar en 1868. Tradujo algunas cartas e informes de Cabrera al inglés en Light and Truth. Probablemente sea el traductor de este opúsculo cuya autoría sospecho que es de Cabrera porque se anuncia como suyo en varias ocasiones en Light and Truth, como en el número 6, de Light and Truth, junio de 1885: 96. 


\section{Diarios o memorandos \\ - Diario G (Gibraltar). En dos cuadernos:}

«Misión. 1. 13 noviembre 1867». Comienza el 13 de noviembre de 1867, en que se hace cargo de la Misión española en la Iglesia Presbiteriana de Gibraltar, y se cierra el 30 de abril de 1868.

«Misión. 2. 1 de mayo de 1868». Comienza el 1 de mayo y termina el 29 de septiembre de 1868 cuando abandona Gibraltar por primera vez.

- Diario S1 (Sevilla). 29 sept-22 abril 1869. Manuscrito original, inédito. 16 cuartillas plegadas y numeradas. Incompleto.

- Diario S2 (Sevilla). 20 sept-30 octubre 1868. Manuscrito original, inédito. 9 cuartillas plegadas y numeradas.

- Memorándum del Pastorado del Rev. Juan B. Cabrera en Madrid. 19 noviembre 1874. Cuaderno primero. Manuscrito original, inédito. Termina el 30 de diciembre de 1900. 192 páginas numeradas, tamaño cuartilla.

- Memorándum del Rectorado del Obispo Juan B. Cabrera en Madrid. 10 de enero de 1901. Manuscrito original e inédito en cuaderno pautado de pastas negras plastificadas, tamaño cuartilla. La portada lleva estampado de imprenta el escudo de España. Termina el 30 de abril de 1916, es decir, 18 días antes de su fallecimiento. 142 páginas numeradas.

Obra en verso conservada

\section{Himnarios}

- Himnario para uso de las iglesias evangélicas coleccionado y en parte compuesto por Juan B. Cabrera, pastor de la Iglesia de la Santísima Trinidad en Sevilla, Sevilla, Imp. de «El Cristianismo», 1871. Contiene 286 himnos de diversos autores y Cabrera suscribe 37.

- Himnario para uso de la Iglesia Cristiana Española, coleccionado y en parte compuesto por Juan B. Cabrera, pastor de la iglesia evangélica del Redentor, Madrid, Imp. de J. Cruzado, Madrid, 1878. Contiene 300 himnos, de los cuales 79, entre originales y traducidos, corresponden a Cabrera.

- Himnario para uso de la Iglesia Española Reformada, coleccionado por el Rev. Juan B. Cabrera, Madrid, Imp. de José Cruzado, 1887 . Contiene 200 himnos y 12 doxologías. Cabrera es autor de 125. Existe reedición como Himnario para uso de la Iglesia Española Reformada Episcopal, Madrid, 1962. Contiene 58 himnos más. En este último figura Cabrera con 85 himnos originales, 46 traducidos o adaptados y 13 doxologías de un total de 20.

- Himnos y canciones para las escuelas diarias y dominicales coleccionados por el Rev. Juan B. Cabrera, Madrid, Imp. de José Cruzado, 1887. (La segunda edición en Madrid, Imp. de B. Izaguirre, 1914). Es simultáneo del Himnario de 1887. Contiene 60 himnos y cuatro doxologías.

Según mi cómputo final, perteneces a Cabrera 97 himnos originales y 47 traducidos, del inglés, principalmente, o del latín.

\section{Poesías}

- Poesías religiosas y morales, Madrid, Estab. Tipográfico de Idamor Moreno, 1904, 511 páginas. Dividido en cinco secciones. Incluye las cuatro poesías profanas conservadas, tres poesías ocasionales, 17 salmos metrificados, 26 poesías infantiles, 144 himnos originales y traducidos de Cabrera insertos en los distintos himnarios, y otros poemas con finalidad eclesial.

- Poesías infantiles, Benissa, Ajuntament. Comissió de Cultura, 1980. Reproducción facsimilar de la parte así titulada en Poesías religiosas y morales.

- Canto memorial. Poema autobiográfico, vertebrado por la acción del autor dedicado al servicio del Evangelio. Se publicó póstumamente en La Luz, en números consecutivos desde el 1.007, correspondiente a enero de 1917, hasta el 1.016, de octubre del mismo año. Lo forman 1.272 versos de distintos metros y formando estrofas diferentes.

- Poesías infantiles, Benissa, Ajuntament. Comissió de Cultura, 1980. Reproducción facsimilar de la parte así titulada en Poesías religiosas y morales.

- «Oda a Valencia». Publicada en La Luz, año XLIII, núm. 942, agosto, 1911: 94-95. Fechada «en Madrid, agosto 1911». Se compone de 22 sextetos de versos heptasílabos y endecasílabos (aBabCC).

- "A Alicante». Apareció como «La última poesía del obispo Cabrera» en La Luz, XLVIII, núm. 1.002, agosto de 1916: 448-449. Se compone de 22 sextetos-lira (aBabCC) de endecasílabos y heptasílabos, como la "Oda a Valencia», más un estrambote de dos pareados.

- «Con saludo cortés y afectuoso». Poema inédito. Sin título. 
APÉNDICE 2.

APROXIMACIÓN CUANTITATIVA AL NÚMERO DE PROTESTANTES ESPAÑOLES

El historiador y teólogo alemán Ernst Hermann J. Schäfer (1872-1946) distingue en Protestantismo español e Inquisición en el siglo XVI82 dos grupos de estudiosos ante la propagación del protestantismo en España: los protestantes y los católicos. Los primeros exageran las cifras y los católicos las disminuyen. Luego existen los contrarios a la Inquisición, como Juan Antonio Llorente (1756-1823) y Adolfo de Castro (1823-1898) que tienden también a la elevación del número.

Según Schäfer, Llorente "afirma una muy amplia propagación de Evangelio en España» ${ }^{83}$; para el protestante Thomas M'Crie (1778-1835) la cantidad de disidentes en el reino de León "llegó a no menos de 2.000 personas». ${ }^{84}$ En nota al pie, Schäfer dice que "es cálculo totalmente arbitrario». ${ }^{85}$ Basten estas palabras para indicar que las cifras son objeto de controversia. Schäfer juzga su postura como desapasionada porque se apoya «sobre la base de las actas ${ }^{86}$ de los autos de fe del siglo XVI.

Por otra parte, evito el término estadística para referirme a la relación numérica de protestantes españoles durante el periodo de las llamadas dos Reformas, la del siglo XVI y la que comienza en 1868 , porque resulta difícil elaborar un censo rigurosamente exacto debido, entre otras cosas, a la maleabilidad natural de las cambiantes creencias religiosas. ¿Consideraremos protestante o católico a un bautizado que en su época adulta ha dejado la práctica religiosa? Entiéndase, pues, lo que sigue como una estimación o aproximación cuantitativa.

\section{SIGLO XVI: PROTESTANTES ESPAÑOLES PROCESADOS}

La historia del protestantismo español tiene un episodio profundamente marcado: los autos de fe del XVI. La existencia en España de seguidores del luteranismo era para Carlos V, cuando supo de los herejes apresados en Valladolid, "una gran desvergüenza y bellaquería», según confesaba a su hija, la regente Juana, en una carta escrita desde su retiro en Yuste el 25 de mayo de 1558. Aconsejaba proceder contra ellos. ${ }^{87}$ Este fue el motivo que impulsó a la regente para que el inquisidor Fernando de Valdés comenzase a actuar. Se desata entonces por Castilla «la histeria antiluterana», como designa este historiador francés a la reacción contra la herejía ${ }^{88}$, cuyo peligro fue deliberadamente aumentado por el propio inquisidor Valdés "para poder quedarse en funciones». ${ }^{89}$

\section{Comunidad protestante de Valladolid}

Un año después de la carta, el 21 de mayo de 1559, se celebra el primer auto de fe contra luteranos en Valladolid. Lo presidió la regente Juana y el príncipe heredero Carlos (el

\footnotetext{
82 Schäfer 2015: I, 373 y ss.

83 Ibídem: I, 376.

84 Ibídem: I, 379.

85 Ídem.

86 Ibídem: I, 412.

87 Pérez 2002: 144.

88 Ibídem: 142.

89 Ídem.
}

rey Felipe II estaba fuera de España). Los acusados fueron 31 , de los cuales uno era judío, según cómputo y relación nominal de Schäfer. ${ }^{90}$ De estos 31 "lleuaron catorze a quemar y la estatua que fueron $15 » .^{91}$ Entre los quemados, el judío. El único quemado vivo fue el bachiller Herrezuelo, natural de Toro: «No se quiso desdecir. Quemárole bibo, con vna mordaza a la lengua». ${ }^{92}$

Los demás fueron vueltos a la cárcel para cumplir sus penitencias. ${ }^{93}$ Al final de la relación: "Se dice que llegó un breve de Su Santidad ordenando que se obrara así, según información del tribunal, por el bien de la Iglesia y para impedir que se propagara la maldad $» .^{94}$

El segundo auto de fe, celebrado del 8 de octubre de 1559 en la capital castellana, estuvo presidido por el rey Felipe II, su hermana Juana y el príncipe. Dice Pérez, quizá simplificando la gravedad, que:

Aquel auto ha pasado a la historia por el supuesto intercambio de réplicas entre el rey y el principal condenado, Carlos de Seso, corregidor de Toro. Se dice que éste le preguntó al rey que cómo consentía aquellas cosas y que Felipe II le habría contestado: "Yo traeré la leña para quemar a mi hijo, si fuere tan malo como vos». Cita la anécdota Cabrera de Córdoba, que escribía cuatro años después del acontecimiento. Sin embargo, hay sobrados motivos para creer que Felipe II nunca pronunció semejante frase..$^{95}$

Como indica después, la frase parece ser un dicho tradicional que podría remontarse incluso hasta Fernando III el Santo (siglo XIII). En cuanto al número de condenados en esta segunda ocasión nos ha dicho de forma muy general este autor francés en La España de Felipe I/ que "se pronunciaron 14 condenas a muerte». ${ }^{96}$ Schäfer, por su parte, contabiliza 28 procesados, más un judío y un mahometano. ${ }^{97}$

Los dos autos de Valladolid computan un total de $58(30+28)$

Tal cifra es la misma o próxima a la que, redondeando, nos da el historiador y sacerdote González Novalín, quien, hablando de la hiperbólica estimación de conversos al luteranismo que se hizo a veces, reduce el número del movimiento castellano a una cincuentena: "Ya está bien si reconocemos aquella experiencia [de la conversión] a los

90 Schäfer 2015: III A, 7 y 22.

91 Ibídem: III A, 22, 45 y 62-63.

92 Ibídem: III A, 21.

93 Ibídem: III A, 23.

94 Ibídem: III A, 45. Semejantes cifras relativas a luteranos aunque más imprecisas, en La España de Felipe // de Pérez: 14 condenados a muerte en la hoguera, previa estrangulación por haberse arrepentido, excepto Antonio Herrezuelo, abogado de Toro, quemado vivo; los otros 16 sufrieron penas menores (Pérez 2000: 56). Jesús Alonso Burgos reduce los herejes luteranos a 29: 13 quemados y 16 reconciliados (1983: 107). Quizá por no computar la estatua.

95 Pérez 2002: 146.

96 Ibídem 2000: 57.

97 Schäfer 2015: III A, 64-86. Jesús Alonso Burgos cuenta 18 luteranos a los que pone nombre y apellidos: 13 quemados y cinco reconcilia$\operatorname{dos}(1983: 114)$. 
cabecillas de la cincuentena que constituía el núcleo del movimiento". ${ }^{98} \mathrm{Y}$ para Jesús Alonso Burgos los encausados en los dos autos de fe de la ciudad castellana rondan también esa cifra o algo inferior: los condenados en los dos autos de Valladolid por luteranos son «apenas cincuenta personas; exiguo número para la enorme relevancia que tuvieron los procesos y para el desmedido interés que autoridades e inquisidores pusieron en ellos"..$^{99}$

El hereje (1998) de Miguel Delibes, novela que narra la penetración de la corriente luterana en Castilla y el corte trágico mediante los autos de fe, tiene como protagonista y agente difusor a Cipriano Salcedo. Lleva el fichero creciente de aquellas personas acogidas a la nueva forma de fe reformada basada en el beneficio de Cristo $^{100}$ y calcula que el número de los presuntos herejes de la villa de Valladolid es de sesenta: «[...] la cárcel secreta resultaría insuficiente para albergar a los presuntos sesenta herejes de la villa». ${ }^{101}$ El narrador repite la cifra, que es la que constituye el total aproximado de los luteranos condenados en los dos autos de Valladolid y que el novelista ha unificado en el primero de ellos: «El cautiverio de los más de sesenta reclusos de la cárcel secreta de Pedro Berrueco, acusados de pertenecer al foco luterano de Valladolid, concluyó definitivamente en la madrugada del 21 de mayo de 1559». ${ }^{102}$

Schäfer, bastantes años antes que Pérez, González Novalín y Alonso Burgos, nos ofrecía, como éstos últimos, una cincuentena larga, exactamente 55 personas. Con distribución geográfica, el historiador alemán elabora la lista nominal de miembros de la comunidad protestante de Valladolid ${ }^{103}$ a partir de las relaciones de auto y con las noticias o actas de los procesos conservados y al final concluye: «Con estas 55 personas está agotado el número de los miembros pertenecientes a la comunidad evangélica de Castilla la Vieja aplastada ya en formación». ${ }^{104}$ La cifra de 55 no coincide exactamente con los 58 arriba indicados, y habría que rebajarla a 54, porque, como ha anotado al pie, la cantidad de 55 «resulta de añadir en el cómputo al inglés Anton Bagor». ${ }^{105}$

\section{Sevilla}

Schäfer reconoce al estudiar este otro importante foco de herejía que «si ante la averiguación de los evangélicos castellanos estábamos en la feliz situación de, a través de noticias de procesos detallados, ver confirmado con seguridad el número de miembros de la comunidad, no es ese, lamentablemente, el caso para Sevilla en igual medida». No obstante, afirma que en ambos casos el número de protestantes fue "muy pequeño» y "no corresponde en absoluto a las descripciones exageradas, por ejemplo, de Montes, que habla de 800 personas que debe haber encarceladas en la Inquisición». ${ }^{106}$

\footnotetext{
98 González Novalín 1980: 229.

99 Alonso Burgos 1983: 64.

100 Delibes 1998: 336.

101 Ibídem: 406.

102 Ibídem: 467.

103 Schäfer 2015: I, 413-443.

104 Ibídem: I, 443.

105 Ibídem: I, 404, n. 127.

106 Ibídem: I, 549.
}

Siguiendo la relación que ofrece el historiador alemán podemos aproximarnos a la cifra total de protestantes españoles condenados en Sevilla en los cuatro autos de fe efectuados entre 1559 y 1562 . Veremos que el número se eleva a 103.

El primer auto se celebró el 24 de septiembre de 1559 y Schäfer conforma una relación nominal de «23 personas en total» penalizadas como protestantes. De ellas, « 16 relajadas en persona, 1 en estatua [quemada], 4 reconciliadas, 1 penitenciada». ${ }^{107}$ Aparte quedan 6 extranjeros.

El segundo auto sevillano tuvo lugar el 22 de diciembre de 1560. En este caso, dice Schäfer que «la suma de evangélicos españoles alcanza según esto a 29 , de los cuales 11 relajados en persona, 3 en estatua, mientras que el número de reconciliados alcanza a 12 , el de los penitenciados a 3 . A eso se añaden 7 extranjeros, 4 españoles y los absueltos». ${ }^{108}$

Se levantó el tablado del tercer auto de la capital hispalense en la Plaza de San Francisco el 26 de abril de 1562. En este tercer caso y según Schäfer, «la suma total de miembros penados de la comunidad sevillana alcanza hasta 29, de los que 6 fueron relajados en persona, 16 en estatua, mientras que, además, 18 extranjeros pagaron diferentes penas por luteranismo y tres españoles por cuestiones luteranas». ${ }^{109}$ Precisemos que a estos sumandos debe añadirse, para llegar a la cifra señalada de 29, los cuatro penitenciados relacionados también por Schäfer junto a los otros 25 en la página anterior. ${ }^{110}$

Por la importancia que revisten en la historia del protestantismo español, hemos de destacar el hecho de que entre los relajados en estatua se encontraba «el mayor número de los frailes huidos de San Isidro». Merecen mención fray Casiodoro de Reina, fray Antonio del Corro y fray Cipriano de Valera. ${ }^{111}$

Finalmente, el 28 de octubre de 1562, hubo un cuarto auto de fe en Sevilla. Afirma Schäfer que en este último castigo público «un gran número de protestantes sevillanos fueron condenados» y contó con una notable participación pública. Después de relacionar los nombres, Schäfer sintetiza el recuento numérico: «Según esto, la suma de los protestantes sevillanos condenados en este auto alcanza a 22: 6 relajados en persona, 2 relajados en estatua, 1 reconciliado en estatua; 13 penitenciados; además, 16 extranjeros y el español Juan de Medina», que, como nos había dicho, abjuró. ${ }^{112}$

107 Ibídem: I, 566. Las personas reconciliadas fueron 5 y no 4, si atendemos a los nombres que Schäfer ha mencionado unas líneas antes: Pero Hernández, Antonio de Cárdenas, fray Benito (lego de San Isidro), Gerónima Ayala y Nicolás Salla.

108 Ibídem: I, 569. Pérez indica con menos detalle en Crónica de la Inquisición en España que «en el segundo auto fueron catorce herejes los que fueron sentenciados a muerte y ejecutados, más tres que lo fueron en efigie, entre ellos el doctor Egidio y el doctor Constantino Ponce de la Fuente» (Pérez 2002: 147). En La España de Felipe II, este mismo historiador había elevado en dos el número. Después de referirse a los dos de Valladolid y al primero de Sevilla, escribe: "Por último, el 22 de diciembre de 1560 se celebró en Sevilla otro auto de fe. Dieciséis personas fueron condenadas a la hoguera, y tres ardieron en efigie. Entonces se dio por erradicado el protestantismo en España» (ibídem 2000: 57).

109 Schäfer 2015: I, 572-573.

110 Ibídem: I, 572.

111 Ídem.

112 Ibídem: I, 474. 
El cómputo total de luteranos condenados en los cuatro autos de fe sevillanos que resumimos por Schäfer se eleva, como adelantamos, a 103.

\section{Dificultades en el cómputo}

Las dificultades para calcular acertadamente el número se debe a que no se conservan todas las relaciones de los autos celebrados. Schäfer supone que entre 1550 y 1600 hubo "aproximadamente 400" autos en las 13 Inquisiciones. ${ }^{113}$ Pero de esos autos sólo se conservan 216 relaciones. Extrapolando los datos de esas relaciones conservadas aporta la siguiente estimación numérica:

En estos 216 autos [de los que tenemos relaciones] fueron penados por presunto protestantismo justamente 110 españoles, de forma que en los 400 autos 200 sufrieron esta suerte; con añadidura de aquellos 125 mencionados en las relaciones anuales resultaría una cifra total aproximada de 325 españoles a los que entre 1550 y 1600 se les hizo proceso de protestantismo, esto es, un promedio de 25 en cada Inquisición, descontadas las dos comunidades de Sevilla y Valladolid. ${ }^{114}$

Conviene aclarar que la cifra de 125 que Schäfer añade a los 200 calculados por extrapolación hace referencia a los protestantes puestos ante la Inquisición y que el tribunal condenó sin auto o los absolvió tras el proceso. Este número de 125 es también estimativo:

Según las relaciones anuales conservadas, fueron entonces procesados en todas las Inquisiciones, sin que siguiera auto, un conjunto aproximado de 50 españoles, de forma que la suma total de todos los llevados ante la Inquisición durante 50 años habría alcanzado aproximadamente 125, esto es, cada tribunal desde 1550 hasta 1600 condenó sin auto o absolvió como promedio total a 9 españoles. ${ }^{115}$

Si he comprendido bien las palabras citadas, a esta cifra estimada por Schäfer de 325 protestantes españoles procesados deben sumarse los 54 de los dos autos castellanos y los 103 resultantes de los cuatro sevillanos. Obtendremos así un cómputo total (aproximado) de 482 protestantes españoles puestos ante la Inquisición durante el siglo XVI.

Esta cantidad, sin embargo, sobrepasa a los 355 luteranos que de forma general e igualmente estimada encontramos en la Crónica de la Inquisición de Pérez para todo el siglo XVI: "Hasta el año 1600 ascienden a 1.995 los casos de luteranismo, de los cuales 1.640 son extranjeros. Probablemente esto da un cuadro bastante exacto de las cifras relativas de las dos categorías». ${ }^{116} \mathrm{O}$ sea, 355 para la categoría de luteranos españoles.

Quizá la diferencia entre las cifras relativas de Pérez y de Schäfer provenga de que el primero sólo considere numéricamente a los procesados con auto seguido al

\section{Ibídem: I, 408}

114 Ibídem: I, 408. Jesús Alonso Burgos, citando a Kamen, también ofrece en el capítulo $V$ de su libro una cifra total de 200 españoles condenados por protestantismo: «Kamen siguiendo a Schäfer, totaliza alrededor de 200 españoles y 1.640 extranjeros condenados por protestantismo en toda España durante la segunda mitad del siglo XVI, con excepción de los de Valladolid y Sevilla» (1983: 121).

115 Schäfer 2015: I, 406.

116 Pérez 2002: 153. procesamiento y no los 125 procesados sin auto o absueltos tras el procedimiento que, en cambio, sí estimó Schäfer, puesto que si a los 355 de Pérez le sumamos 125 de Schäfer obtenemos 480 , cifra casi totalmente coincidente con la de aquellos protestantes españoles que el historiador y teólogo alemán calculó que fueron puestos ante la Inquisición y procesados, con auto y sin auto.

\section{Escasa cosecha}

Según Schäfer, estas cifras de protestantes españoles puestos ante la Inquisición en el siglo XVI no permiten afirmar que hubo una gran propagación de seguidores del credo evangélico "en un país de al menos 10 millones de habitantes». ${ }^{117}$ Desde su estimación impugna la postura de los evangélicos y de Federico Fliedner ${ }^{118}$, cuya tesis, según Schäfer, defendía que «en el siglo de la Reforma muchos miles de protestantes sufrieron en España la muerte en la hoguera». ${ }^{119}$ Schäfer se opone al alcance milenario que del protestantismo española hace Fliedner, porque, siguiendo a Llorente, el pastor alemán asentado en España en el siglo XIX no especifica si se refiere a protestantes españoles o no. Los cálculos exageradamente elevados de Fliedner sobre los protestantes asesinados por la Inquisición son, para su compatriota Schäfer, erróneos e inexactos. ${ }^{120}$

Por otro lado y a pesar de que Marcel Bataillon suscitó la duda de si todos los protestantes condenados por la Inquisición en los autos de fe de Valladolid y Sevilla lo eran efectivamente, hoy no se acepta esa duda. Pérez coincide con José Ignacio Tellechea y afirma con seguridad en La España de Felipe I/ lo siguiente:

No cabe duda de que los condenados por la Inquisición en 1559-1560 en dos de las principales ciudades del reino eran protestantes, aunque al principio se exageró interesadamente su número. Después de 1560 siguieron entrando en España libros protestantes, sobre todo calvinistas, pero los escasos protestantes que comparecieron ante la Inquisición eran extranjeros, franceses, ingleses o alemanes, residentes en España o, más a menudo, comerciantes y marinos que estaba de paso. ${ }^{121}$

Luego en este mismo libro Pérez considera que si la semilla del protestantismo no arraigó en España fue por dos razones principales, aparte la represión inquisitorial: las reformas de la disciplina eclesiástica introducidas al principio del siglo y la corriente original del iluminismo. ${ }^{122}$ El éxito, pues, fue escaso. En Crónica de la Inquisición Pérez añade la renovación teológica a las tres razones anteriores para explicar en escaso éxito:

¿A qué se debe el poco éxito del protestantismo en la Península? Sería erróneo atribuir este hecho solamente al control inquisitorial; las medidas de censura y persecución no fueron obstáculo en ningún país para

\footnotetext{
117 Schäfer 2015: I, 408.

118 Ibídem: I, 383.

119 Ibídem: I, 409.

120 Ibídem: I, 412. Antes ha dicho sobre las exageraciones del alcance del protestantismo que con tal ponderación «no solo no se presta ningún servicio a la buena causa del Evangelio, sino que se le ocasiona el más grave daño» (ibídem: I, 377).

121 Pérez 2000: 58-59.

122 Ibídem: 59.
} 
que floreciera el protestantismo. Resulta más apropiado invocar otros argumentos: la lejanía del epicentro de aquel terremoto espiritual y hasta cierto punto la reforma interna de la Iglesia promovida por los Reyes Católicos en cuanto al episcopado y las órdenes religiosas, así como la renovación de la teología en Salamanca y Alcalá. Pero la verdadera explicación es que, en España, las inquietudes religiosas se orientaron hacia otra dirección, la del iluminismo. ${ }^{123}$

Aparte las pequeñas diferencias del cómputo y aparte las razones en que se basen los historiadores para hablar del grado de arraigo del protestantismo en el siglo XVI, existe coincidencia en afirmar que el luteranismo terminó en España con los autos de fe del siglo XVI. Menéndez Pelayo aseguraba en Historia de los heterodoxos que "con estos dos autos quedó muerto y extinguido el protestantismo en Valladolid». ${ }^{124}$ Alonso Burgos escribe en el último párrafo del libro: «El problema del luteranismo en España queda zanjado en los albores del siglo XVII». ${ }^{125}$ Unas páginas antes deja constancia de que "el único caso conocido de protestantismo español durante el siglo XVII» fue el de un calvinista franciscano llamado Ferrer. ${ }^{126}$

Efectivamente, durante los siglos XVII y XVIII no encontramos uvas granujas del racimo protestante. Tellechea Idígoras igualmente afirma sin titubear que el efecto de los magnos autos de fe de Valladolid y Sevilla:

Fue el total aplastamiento del protestantismo en España. Así lo reconoce el mismo Schaefer [sic]. Entonces terminó el protestantismo español para varios siglos. Hubo protestantes españoles fuera de España. El escaso tiempo para su arraigo, el descubrimiento temprano de sus núcleos y la violenta represión, borraron del mapa religioso y cultural español los retoños protestantes. Perduró, sin embargo, indirectamente en la forma de una aversión cordial, sostenida durante mucho tiempo, y de la que da muestras la misma literatura profana. ${ }^{127}$

Junto a la represión violenta, pues, hay que considerar la aversión que ha perdurado hasta prácticamente nuestros días. De modo que las causas de la escasa cosecha no me parece que la distancia del foco original luterano fuese muy importante, como dice Pérez. De haber sido así, no hubiera existido la aversión secular de la que habla Tellechea Idígoras. A mí me parece que habría que considerar para el cómputo también del protestantismo en los siglos XIX y XX esa aversión, condesada en púlpitos y en formas jurídicas, porque ambas instancias (altar y trono) crean la disposición de ánimo excluyente ante lo diferente. Para los protestantes Araujo García y Grubb, el protestantismo en España no ha progresado debido al «fanatismo y la persecución». ${ }^{128}$

\section{SIGLOS XIX-XX: SEGUNDA REFORMA}

Habría que esperar hasta el siglo XIX para poder respigar en ese campo, segado por completo a guadaña. La semilla

\footnotetext{
123 Ibídem: 153.

124 Menéndez Pelayo 1986: I, 966.

125 Alonso Burgos 1983: 123.

126 Ibídem: 120.

127 Tellechea Idígoras 1977: 29.

128 Araujo García y Grubb 1933: 38.
}

vendría otra vez del exterior. Un notable sembrador fue George Borrow, agente de la Sociedad Bíblica Británica y Extranjera. Borrow llegó a Lisboa el 12 de noviembre de 1835 y cruzó la frontera entre Portugal y España el 5 de enero de 1836, "montado en una triste mula, sin riendas ni estribos», según leemos en La Biblia en España. ${ }^{129}$ Este fue su primer viaje. Luego volvería dos veces más. Los textos sagrados que repartió no fueron los traducidos por Casiodoro de Reina y Cipriano de Valera, pertenecientes al sevillano convento de San Isidoro. Esos eran tan desconocidos en España como los seguidores de las doctrinas reformadas. El caso es que Borrow es el precedente, junto con Luis de Usoz de la llamada Segunda Reforma, cuyo comienzo hemos de fijar tras la revolución de 1868. Anoto ahora algunos datos estadísticos de la Segunda Reforma.

Debo advertir previamente de que cuando se habla de estadísticas protestantes contemporáneas ha de tenerse en cuenta que bajo el concepto de protestante caben dos categorías: la de miembros comulgantes, que forman parte del registro eclesial; y la de asistentes o congregantes que siendo protestantes, carecen de ese vínculo formal. Además, debemos considerar que algunas denominaciones practican el bautismo de adultos y por tanto sus hijos, no bautizados todavía, son de hecho protestantes asistentes, pero no se pueden considerar como miembros comulgantes. Por tanto al leer los datos que siguen habrá que fijarse bien en el concepto bajo el cual se computan.

\section{Periodo constitucional de 1869}

Carezco de datos que permitan hacer un recuento del número de protestantes durante el Sexenio democrático, pero se observa que hay un alto número de simpatizantes en los momentos que siguen a la revolución de 1868 y luego un descenso de ese interés.

\section{Hughey y Noyes: alto número de simpatizantes}

A este respecto de atracción y enfriamiento alude Hughey en Los Bautistas en España. Reconoce que esta denominación no ofrece datos estadísticos «impresionantes». Y «lo mismo podría decirse de cualquier otra denominación trabajando en España». Según Hughey, refiriéndose a la labor misionera del profesor norteamericano William I. Knapp:

La curiosidad inicial tocante al protestantismo, que llenó las capillas en los meses siguientes a la revolución de 1868, pronto se satisfizo. Así como Knapp pudo enlis$\operatorname{tar} 1.325$ convertidos en sus primeros siete meses de estancia en España, hubo que informar que en 1873 solamente se habían registrado 200 personas como miembros de iglesia, y 244 al año siguiente. El mayor número alcanzado fue en 1876 con 250 bautistas en toda España. ${ }^{130}$

Este fenómeno que Hughey observa en relación con la labor misionera de Knapp se aprecia igualmente en la labor de Cabrera en Sevilla. Cuando se abrió la iglesia de San Basilio de la calle Relator el 11 de julio de 1871, tres años después de la libertad religiosa, la concurrencia superó los

\footnotetext{
129 Borrow 1970: VIII, 108
}

130 Hughey 1985: 31. 
mil asistentes, muchos por curiosidad, según Noyes: «By the time the service commenced there were about 1,200 persons present. Some (about 200) well understood the purpose of the gathering, but the greater part had come out of curiosity, for this was the first public service of what is now known as the Reformed Spanish Church». ${ }^{131}$

En 1875: Vicente Cárcel Ortí y la Nunciatura: 400 congregantes aproximadamente en Madrid

Se advierte en el trabajo de este historiador la preocupación pontificia ante el protestantismo en España y el deseo de bloquear su expansión. El cardenal Antonelli, secretario de Pío IX, pidió el 12 de julio de 1875 al nuncio Simeone residente en Madrid un informe sobre la situación del protestantismo en España. En él se comunica el número de escuelas y capillas existentes en cada diócesis, pero apenas se ofrecen datos precisos en cuanto el número de congregantes, a excepción de Madrid-Toledo, diócesis que en la capital de España contaba en 1875 con nueve capillas y nueve escuelas. Del recuento que personalmente efectúo sobre los datos aportados al nuncio por el vicario apostólico de Madrid $^{132}$, se desprende que el número de escolares en la capital de España está próximo a 450 y el de los congregantes rondará la cifra de $400 .{ }^{133}$

\section{Periodo constitucional de 1876}

\section{En 1878: Juan Bautista Cabrera: 10.000 congregantes}

La información episcopal facilitada al nuncio tiende a minusvalorar la estadística, si tenemos en cuenta los datos que facilita Juan Bautista Cabrera en un informe o "Report» correspondiente a 1878. En versión inglesa queda recogido en Report of the Spanish and Portuguese Mission... Cabrera señala que profesan el cristianismo evangélico en España unas 10.000 personas y 5.000 niños asisten a las escuelas. ${ }^{134} \mathrm{Y}$ en relación con su obra en la iglesia madrileña de Madera Baja notifica que según el último informe de fines de 1878 existen 226 familias, que forman un total de 506 individuos, con 302 comulgantes; $y$ 96 niños y niñas reciben enseñanza en la escuela. ${ }^{135}$

\section{Noyes 1897: 1}

132 Cárcel Ortí 1984: 108.

133 Existen nueve capillas, pero sólo se facilita el número y de forma imprecisa de siete de ellas. Redondeando las cifras se obtiene un resultado de 308 asistentes. Ello supone una media de 44 asistentes por capilla, cantidad que aplicada a las dos no especificadas nos arroja el número de 396.

134 Cabrera 1879: 10.

135 Ibídem: 13. Ofrece los mismo datos redondeados en su participación en la conferencia de Lambeth, celebrada en julio de 1878 (Spanish and Portuguese Church Missions. A Communication from His Grace Lord Archibishop of Canterbury and Letters from the Right Hon. And Right Rev. Lord Plunket, Bishop of Meath and the Right Rev. Henry Chauncey Riley, D.D. Bishop of Valley of Mexico, Offices of the Mission, London, printed by L. Hepworth, pp. 10-22). Al año siguiente la congregación de Madera Baja no experimenta muchos cambios, según otro informe publicado en Spanish and Portuguese Church Aid Society and Mexican Episcopal Church Aid Fund, for the Year Ending March 31st, 1880. De su congregación en Madrid dice ahora que "at the close of 1879» el número de congregantes es de 237 familias que comprenden un total de 456 individuos de los que 336 son comulgantes. La escuela imparte enseñanza a 50 chicos y 48 chicas (8). La misma información Light and Truth 1, January, 1881: 12.

\section{En 1887: 9.194 congregantes}

La Revista Cristiana ${ }^{136}$, dirigida por Federico Fliedner, facilitaba datos estadísticos bajo el epígrafe «Estadística de las Iglesias Evangélicas en España en el año 1887 (31 de diciembre)». Se dice en nota final que se ha confeccionado con la colaboración de los directores de misiones e iglesias. Los datos del corto número de misiones que no ha facilitado informes se han suplido por medios indirectos. Por tanto esta estadística «es la más completa y auténtica posible». ${ }^{137} \mathrm{Me}$ limito a los campos principales: número de locales de culto y escuelas: 112; pastores: 56; evangelistas: 35 ; asistentes a los cultos: 9.194; miembros comulgantes: 3.442 ; escuelas diarias: 111, asistentes a ellas 2.545 niños y 2.095 niñas; escuelas dominicales: 80 , asisten a ellas 3.231 niños de ambos sexos. ${ }^{138}$

Por otra parte, en The Dictionary of Religion..., encontramos la entrada titulada "Spanish Reformed Church». ${ }^{139} \mathrm{El}$ anónimo autor, que parece ser anglicano, dice que el conjunto de congregaciones de la Iglesia Española Reformada de Cabrera reúne alrededor de 2.000 personas: "About two thousand in Spain, and about one thousand in Portugal, may be counted as belonging to their ranks. But the congregations into which they are gathered occupy important centres in these two countries. In Spain they are to be found in Madrid, Sevilla, Málaga, Salamanca, Valladolid, and in the neighbourhood of Barcelona». ${ }^{140}$

\section{En 1910: Packer: entre 12.000 y 15.000 protestantes}

Packer, periodista neozelandés y viajero por Europa, publicó en 1912 Among the Heretics in Europe. Basa su estimación numérica para el caso de España en el documento que en 1910 ha sido presentado al Parlamento en favor de la libertad religiosa. Asegura que va acompañado de no menos de 150 mil firmas, encabezadas por Juan Bautista Cabrera y Cipriano Tornos Blasco. ${ }^{141}$ Y más adelante, Packer aporta estos datos, relativos a $1910^{142}$ : "The Protestant community in Spain is reckoned to number from 12,000 to 15,000 souls». ${ }^{143}$

En 1930: Hernández Figueiredo y los prelados: 10.732 protestantes en España

El 1 de marzo de 1930 el nuncio Tedeschini envió una circular a los obispos españoles pidiéndoles datos exactos sobre las confesiones protestantes existentes en las respectivas diócesis. Con la información enviada a la Nunciatura elaboró un informe entre marzo de 1930 y febrero de 1931 para responder a la preocupación del papa Pío XI (pontífice entre 1922 y 1939). José Ramón Hernández Figueiredo, perteneciente al Instituto Teológico Compostelano, ha estudiado en Hispania Sacra los datos aportados por los prelados. Observa que «se tiene un total definitivo de 10.732

\footnotetext{
136 Anónimo 1888: 352.

137 Ídem.

138 Ídem. Christ suministraba la cifra de 12.000 protestantes para 1886 (circa 1893: 336).

139 Anónimo 1887: 982-984.

140 Ibídem: 983.

141 Packer 1912: 152

142 Ibídem: 160 y 164.

143 Ibídem: 159.
} 
protestantes». ${ }^{144}$ Hernández Figueiredo considera que «esta cifra es ligeramente inferior a aquélla fijada por el Gobierno en 11.227 protestantes ${ }^{145}$, y sensiblemente inferior a aquélla que da el escritor católico Eduardo Navarro Salvador, que después de varios estudios prolijos, fijó en quince mil el número de protestantes en España». ${ }^{146}$ No obstante, para Hernández Figueiredo «la cifra ofrecida por los prelados es la más optimista, evidentemente por la insuficiencia de los datos», que, no permiten «ni siquiera conjeturar el número aproximado de los protestantes». ${ }^{147}$ Después manifiesta que ante esas cifras «el fracaso es evidente, y se ha confirmado cuanto decía Balmes, esto es, que el protestantismo no encuentra aquí ambiente propicio». ${ }^{148}$

No deja de tener razón Hernández Figueiredo con estas últimas palabras, pues, quizá sin darse cuenta, está afirmando, aunque en otro sentido, que, efectivamente, «el protestantismo no encuentra aquí ambiente propicio». ${ }^{149}$ Para percatarse de esta aseveración, basta examinar el ordenamiento jurídico español en el que se desarrollan las dos Reformas en España: la Inquisición nace en 1478 y se prolonga hasta 1834; sumemos a eso el espíritu intolerante e imperativo del centenario Concordato de 1851-1953 («[...] la religión Católica, Apostólica Romana sigue siendo la única de la Nación española») y las Constituciones que desde 1868 hasta 1930 han estado vigentes. Nos daremos cuenta de la efímera y fugaz duración de los periodos «propicios» o con libertad en materia religiosa: prácticamente en el Sexenio Democrático.

\section{Periodo constitucional de 1931}

\section{En 1932: Araujo y Grubb: 22.000 congregantes}

Los protestantes Araujo García y Grubb han elaborado una estadística en La religión en la República española [1933] relativa a la implantación del protestantismo en la actualidad de entonces. Afirman, en resumen, que tras 64 años de trabajo, es decir, desde 1868 hasta 1932, el número de protestantes ronda los 22.000:

Hay 166 congregaciones locales con 6.259 miembros comulgantes; no incluimos aquí un número considerable de pequeños centros o núcleos. Existen además 48 Ministros ordenados; 94 evangelistas y colportores, que dedican todo su tiempo a la obra evangélica; se cuentan 125 extranjeros, de los cuales el 50 por 100 son de los Hermanos. El número total de protestantes en España es cerca de 22.000 . Este es el resultado de sesenta y cuatro años de trabajo; nuestras estadísticas, si no del todo exactas, son, a lo menos, muy aproximadas. ${ }^{150}$

Luego recogen algunas estimaciones relativas a años intermedios de este largo periodo de más de seis décadas:

144 Hernández Figueiredo 2011: 368.

145 Ibídem: 310.

146 Ibídem: 368

147 Ídem.

148 Ídem.

149 Ídem.

150 Araujo García y Grubb 1933: 37. El también protestante Claudio Gutiérrez Marín ofrece esos mismos datos estadísticos «hasta el primer tercio del siglo veinte» (1942: 397): «El número de alumnos matriculados en los colegios protestantes pasa actualmente de los 7.000, siendo aproximadamente igual el número de niños, de ambos sexos, que asisten a la Escuela Dominical. La población evangélica puede calcularse en unas 22.000 almas» (ibídem: 399).
«En 1886 ya se dijo que el número de españoles protestantes eran [sic] unos $12.000 » .{ }^{151}$

\section{Durante la guerra y el franquismo}

\section{En 1939: Vilar: 7.000 comulgantes y 10.000 congregantes}

El catedrático de la Universidad de Murcia Juan Bautista Vilar, partiendo de esa cifra de Araujo García y Grubb, sostiene que durante la contienda «una cuarta parte [de esos 22.000] residía en el sector controlado por Franco ${ }^{152}$ donde eran considerados comunistas o masones y objeto de persecuciones, atropellos y asesinatos, especialmente durante los primeros meses de enfrentamiento. El balance tras la guerra es desalentador, en pérdidas humanas y en bienes materiales. El mismo profesor, Vilar había aportaba dos años antes estos datos:

[...] de 147 localidades con obra protestante en julio de 1936, tres años después sólo 33 contaban con capillas en buenas condiciones de funcionamiento. Los restantes edificios destinados al culto y servicios auxiliares habían sido asaltados, saqueados, destruidos o incendiados. Las cifras demográficas no resultan más alentadora: los 22.000 protestantes españoles de 1936 habían quedado reducidos a la mitad: 7.000 miembros comulgantes, aparte un número de catecúmenos difícil de precisar. Total unas 10.000 personas aproximadamente. ${ }^{153}$

\section{En 1950: Vilar: 20.000 congregantes}

En otro extenso trabajo, "Minorías protestantes bajo el franquismo (1939-1953)», el profesor Vilar da los mismos datos, aunque señala que los 10.000 de 1939 se duplican hacia 1950 y en la actualidad [1980] los protestantes comulgantes «sobrepasan las 100.000 unidades». ${ }^{154}$ En este trabajo se refiere también a la depuración política ${ }^{155}$ y a las discriminaciones, civil, laboral y a los cierres de colegios sufridas por los protestantes. ${ }^{156}$

\section{En 1961: Memorándum del Gobierno: 15.000 españoles y 15.000 extranjeros}

El historiador Vicente Cárcel Ortí es el preparador de la edición de Actas de las conferencias de metropolitanos españoles (1921-1965) y en el estudio histórico-jurídico que las precede describe la postura del episcopado español acerca de la libertad religiosa, siempre a remolque de los acontecimientos, de la siguiente manera:

Los obispos españoles se opusieron hasta el final mismo del Vaticano II a toda modificación de la postura tradicional de la Iglesia en materia de tolerancia religiosa. Pero, una vez aprobada por el concilio y promulgada por Pablo VI la declaración Dignitatis humanae (7 diciembre 1965), la hasta entonces legítima oposición se cambió en adhesión sincera. ${ }^{157}$

\footnotetext{
151 Araujo García y Grubb 1933: 38.

152 Vilar 1987: 11.

153 Ibídem 1985: 229-230.

154 Ibídem 1981: 336. De igual manera en 2001: 257.

155 Ibídem 1981: 343-348.

156 Ibídem: 348-357.

157 Cárcel Ortí 1994: 139.
} 
En estas Actas reproduce Cárcel un Memorándum del Gobierno español (apéndice XII) sobre las confesiones no católicas. ${ }^{158}$ No tiene fecha, "pero [fue] redactado a finales de $1961 » .{ }^{159}$ En él se sigue llamando «sectas» a las distintas denominaciones protestantes ${ }^{160}$, y a juicio de los inspiradores del documento, quienes «suponen hoy en día un efectivo problema» son los "cristianos disidentes», en concreto, "los seguidores de la herejía protestante». ${ }^{161}$ Sobre la cuantía, el Memorándum admite que los cálculos «cifran alrededor de 15.000 el número de los protestantes de nacionalidad española». A ellos se suman "otros tantos» extranjeros "que residen habitualmente, a veces desde generaciones, en España», hasta llegar a «un total de 30.000». ${ }^{162}$

\section{En 1975: López Rodríguez: 35.000 miembros}

El periodista protestante Manuel López Rodríguez publicó en 1976 La España protestante. Aporta cifras acerca del protestantismo al final de la dictadura ${ }^{163}$ y también la distribución geográfica de las distintas denominaciones. Anota la estimación aproximada que ha realizado Juan Estruch en 1968, oscilante «entre 13.816 y 16.470 , referida a 1967». ${ }^{164}$ Se refiere también al cálculo de Dale G. Vought que es de 30.000 para $1972^{165}$, y el propio López Rodríguez calcula en 35.000 el número de miembros para el año $1975 .{ }^{166}$ No comparte la estimación de que «en 1975 se empieza a hablar de 45.000 protestantes, e incluso de 70.000». Para él, esta última cifra "es obviamente generosa» y piensa que tal vez «corresponda al número total de acatólicos, incluyendo Testigos de Jehová, Adventistas, etc., pero esos grupos no protestantes están tan distantes del protestantismo español como la Iglesia Católica romana». ${ }^{167}$

\section{En la época democrática}

En 1976: Aimé Bonifas: 40.000 miembros y en torno a 110.000 congregantes

El pastor francés Aimé Bonifas realiza igualmente sus estimaciones en Quand fleurit l'amandier: $30 \mathrm{mil}$ miembros comulgantes («membres actifs») en 1967 y en 1976 el número puede fluctuar entre 39.390 y $43.380 . .^{168}$ Luego complementa la información diciendo que la cifra redondeada de cuarenta mil miembros activos debe multiplicarse para calcular el número de «simpatizantes». En este sentido, considera que «le chiffre de 100.000 à 120.000 protestants espagnols peut être avancé comme digne de

\footnotetext{
158 Ibídem: 134 y 715-759.

159 Ibídem: 715 .

160 Ibídem: 718, 721.

161 Ibídem: 720.

162 Ibídem: 721.

163 López Rodríguez 1976: anexo 1, 199-205.

164 Estruch 1968: 200.

165 Según el protestante José Grau (1931-2014), la cifra de 30.000 en 1972 «puede tenerse por correcta» (1972: 32). Estruch ofrece la misma (1968: 37-38). Jesús Fernández Santos maneja el mismo número en Libro de las memorias de las cosas (2012: 142) cuando los habitantes en España eran de 35 millones (ibídem: 445).

166 López Rodríguez 1976: 200 y 236.

167 Ibídem: 200. También recoge las librerías, los periódicos, instituciones, colegios y hogares.

168 Bonifas 1976: 68.
}

foi pour $1976 »^{169}$ y que tal cifra, entre una población de 35 millones de habitantes, «n'est pas insignifiant». ${ }^{170}$

En 1990: Gabino Fernández Campos: 71.449 miembros y 215 mil congregantes

El pastor e historiador Gabino Fernández Campos, autor de Compendio cristiano español: Iglesias y misiones (1991), elabora una tabla estadística que refleja sintéticamente la evolución de la membresía protestante. (Recordemos la diferencia entre el concepto de miembros o personas comulgantes o formalmente vinculadas a una congregación y el de comunidad o número de protestantes congregantes).

Según los datos del protestante Fernández Campos, en 1874 el número de miembros era de 1.840. Tres años después se incrementa a 3.442. En 1932 los miembros llegan a 6.053 y a 13.816 en 1960. Veinte años después se alcanza la cifra de 36.722 y en 1990 son ya 71.449 los miembros de iglesias o de congregaciones. Apunta Fernández Campos un factor de multiplicación para estimar el número de congregantes: «En cada caso, podemos multiplicar la cifra dada por tres para obtener un volumen más realista de la comunidad evangélica española». ${ }^{171}$

En 1999: Manuel López Rodríguez: 150 mil miembros y 350 mil congregantes en 1999

El citado periodista Manuel López Rodríguez publicó en 2002 otro trabajo titulado «La asignatura pendiente: nuestra participación política». Contiene también una tabla de crecimiento de los protestantes: va de los 4.000 en 1874 (cuando España tenía 16 millones de habitantes) a 350.0000 en 1999 (año en que la cifra de habitantes ascendía a 40 millones). ${ }^{172}$ Luego especifica que de esos 350.000 protestantes sólo «150.000 son miembros comulgantes de iglesias evangélicas» y que las otras « 200.000 personas [son] de la llamada 'área de influencia', que corresponde a hijos de protestantes y otros simpatizantes o asistentes que no se han comprometido formalmente como miembros practicantes». ${ }^{173}$

\section{SIGLO XXI}

\section{En 2004: FEREDE: 200 mil miembros y 400 mil congregantes}

La Federación de Entidades Religiosas de España (FEREDE), que aglutina y representa a la mayoría de las Iglesias Evangélicas del país, realiza un informe bajo el título «Datos estadísticos» (web), donde se lee:

\footnotetext{
169 Ibídem: 69.

170 Ídem.

171 Fernández Campos 1991: 7.

172 López Rodríguez 2002: 96.

173 Ídem. En las páginas 97-98 se encuentra un cuadro «aproximativo» de las principales denominaciones y el número de congregaciones correspondientes a cada una de ellas. Según esa información, las tres denominaciones con mayor número de congregaciones son las Iglesias de Filadelfia, los Bautistas, las Iglesias Pentecostales y las Asambleas de Hermanos.
} 
Actualmente, en España, hay aproximadamente 1.200.000 protestantes. Esta cifra se obtiene mediante la suma de los siguientes colectivos:

- 400.000 personas (la gran mayoría españoles, que se congregan habitualmente en las iglesias evangélicas. La mitad de esta cifra corresponde a miembros comulgantes de iglesias evangélicas y la otra mitad conforman la llamada "zona de influencia» que corresponde a hijos de protestantes y otros asistentes o simpatizantes que no se han comprometido formalmente como miembros practicantes.

- 800.000 protestantes comunitarios y extracomunitarios residentes en España más de seis meses.

Luego muestra el proceso estadístico de congregantes observado a lo largo de la historia, desde 1874, hasta los primeros años del siglo XXI. El cuadro es aproximativo, pero puede servir de síntesis. Se notará el contraste entre 1932 y 1939. En 1874 había 4.000 congregantes evangélicos cuando la población era de 16 millones. En 1932, la población española ascendía a 24 millones y el número de protestantes alcanzaba la cifra de 22.000. Este número, que ya conocemos, se redujo a 7.000 en 1939 cuando, por el contrario, la población aumentaba hasta los 29 millones. En el año 2000, los congregantes evangélicos eran 350.000, cifra que se incrementaba en 2004 hasta 400.000 y la población española contaba con 42 millones. A continuación del cuadro declara: "No disponemos de datos sobre la evolución de la residencia en España de la población protestante extranjera que reside más de seis meses en nuestro país».
En 2015: Ministerio de Justicia: 500 mil congregantes y la mitad de comulgantes o miembros

La Secretaría General Técnica del Ministerio de Justicia publicó en 2016 el Informe anual sobre la situación de la libertad religiosa en España 2015 (web). Extracto lo relativo a los protestantes en dos aspectos principales: lugares de culto y número de fieles. Respecto del primer concepto: "Según datos ofrecidos por el Observatorio del Pluralismo Religioso, a fecha de 1 de junio de 2015, existen 3.588 lugares de culto evangélicos, que suponen un $12,22 \%$ del total de los lugares de culto existentes en España, y un $57,22 \%$ con respecto a los de las minorías religiosas $»{ }^{174}$

Y a propósito del número de fieles evangélicos o protestantes, el informe señala que la FEREDE «no dispone de datos estadísticos actualizados», aunque "aporta las siguientes estimaciones obtenidas de un estudio que se realizó hace 10 años». El informe distribuye los datos en tres categorías: congregantes, no congregantes comunitarios y no congregantes extracomunitarios:

- Para la primera, «se estima en 500.000 » el número de "personas que se congregan en las iglesias evangélicas».

- Respecto de la segunda categoría, dice que son «entre 800.000 y 1.000 .000 las personas [protestantes] procedentes de la Unión Europea que residen en España más de seis meses al año», pero son «no congregantes».

- Y para los no congregantes extracomunitarios calcula un número oscilante «entre 100.000 y 150.000 personas procedentes fundamentalmente de la Europa no comunitaria, América Latina, Asia y África».

Y concluye el informe: "La suma de estas estimaciones estaría en torno a 1.500.000 protestantes en España». ${ }^{175}$

\footnotetext{
174 Ministerio de Justicia 2016: 14
}

175 Ibídem: 15 . 


\section{Bibliografía CITADA}

Alonso Burgos, J. 1983. El luteranismo en Castilla durante el siglo XVI. Autos de fe de Valladolid de 21 de mayo y de 8 de octubre de 1559. San Lorenzo de El Escorial: Swan.

Anónimo. 1887. "Spanish Reformed Church», en W. Benham (ed.), The Dictionary of Religion: an Encyclopedia of Christian and other Religious Doctrines, Denominations, Sects, Heresies, Ecclesiastical Terms, History, Biography, etc. etc.: 982-984. London, Paris, New York, Melbourne: Cassell and Company.

Anónimo. 1888. «Estadística de la Iglesias Evangélicas en España en el año 1887 (31 de diciembre)». Revista Cristiana 214: 352.

Anónimo. 1894. «El asunto del día», en La Luz XXVI, núm. 694, 30 de septiembre: $212-214$.

Araujo García, C. y Grubb, K. [1933]. La religión en la República española. Madrid: Sociedad de Tratados Evangélicos. [Trad. abrev. del inglés por J. Orts González].

Arencón Edo, R. 2000. Nuestras raíces. Pioneros del protestantismo en la España del siglo XIX. Barcelona: Recursos Ediciones.

Bonifas, A. 1976. Quand fleurit l'amandier. Les protestants d'Espagne. Paris: Les Bergers et les Mages.

Borrow, G. 1970. La Biblia en España. O viajes, aventuras y prisiones de un inglés en su intento de difundir las Escrituras por la Península. Madrid: Alianza Editorial. [Introd., n. y trad. de M. Azaña].

Cabrera, J. B. 1879. "Report», en L. S. Tugwell (ed.), Report of the Spanish and Portuguese Mission for the Yeard Ending March 31, 1879: 4-14. London: Offices of the Mission (printed by C. A. Macintosh).

Cabrera, J. B. 1904. Poesías religiosas y morales de Juan Bautista Cabrera. Madrid: Est. Tip. de Idamor Moreno.

Cabrera, J. B. 1907. «La Iglesia del Redentor de Madrid», en La Luz 894 254-256; 896: 268-270; y 897: 276-278. [Serie de tres entregas].

Cabrera, J. B. 1914. "Una rectificación», en La Luz XLVI, marzo: 34-35.

Cabrera, J. B. 1917. «Canto memorial», en La Luz: 1.007-1.016.

Cabrera, J. B. Inédito. Diario G o de Gibraltar. Formado por dos cuadernos pequeños con estas portadas: «Misión. 1. 13 Noviembre 1867» y "Misión. 2. 1 de mayo de 1868». En el archivo y biblioteca de la Iglesia Española Reformada Episcopal, Madrid. [Sin catalogar].

Cabrera, J. B. Inédito. Diario S1 o de Sevilla. Continuación de Diario G. Manuscrito de 16 pliegos de cuartilla. Comienza el 29 de septiembre y termina el 22 de abril de 1869. Le faltan el 14 y los que siguen al 16. Biblioteca personal de Rosario Morales Cabrera.

Cabrera, J. B. Inédito. Diario S2. Primer viaje a Sevilla. Abarca desde el 20 de septiembre al 30 de octubre de 1868. Manuscrito de 9 cuartillas plegadas y numeradas. Biblioteca personal de Rosario Morales Cabrera.

Cabrera, J. B. Inédito. Memorándum del Pastorado del Rev. Juan B. Cabrera en Madrid. 19 noviembre 1874. Cuaderno primero. Manuscrito. Manejo fotocopia. Termina el 30 de diciembre de 1900. 192 páginas numeradas, tamaño cuartilla.

Cabrera, J. B. Inédito. Memorándum del Rectorado del Obispo Juan B. Cabrera en Madrid. 10 de enero de 1901. Manuscrito original en cuaderno pautado de pastas negras plastificadas, tamaño cuartilla. En la portada, estampado de imprenta el escudo de España. Termina el 30 de abril de 2016. 142 páginas numeradas.

Capó i García, B. y Cardona Ivars, J. J. (comps.) 1985. Antología de escritores benisseros. Benissa: Ajuntament de Benissa, Comissió de Cultura.

Capó, B. 1979. "Los hermanos Cabrera Ivars, de Benisa». Revista del Instituto de Estudios Alicantinos 28: 129-140.

Cárcel Ortí, V. 1984. "Acatólicos españoles en los albores de la Restauración». Anales de Historia Contemporánea 3: 101-121.

Cárcel Ortí, V. (ed.) 1994. Actas de las conferencias de metropolitanos españoles (1921-1965). Madrid: BAC.

Christ, E. [circa 1893]. Héroes españoles de la fe. Cuadros de la Reforma. Madrid: Librería Nacional y Extranjera.

Codding, M. A. 2000. «El alma de España en un museo: Archer Milton Huntington y su visión de The Hispanic Society of America», en P.
Lenaghan (ed.), The Hispanic Society of America. Tesoros: 15-37. New York: The Hispanic Society of America.

Corvillón, B. y Vidal, D. 1973. "Reforma protestante», en Q. Aldea Vaquero, T. Marín Martínez y J. Vives Gatell (dirs.), Diccionario de Historia Eclesiástica de España, III: 2063-2065. Madrid: Instituto Enrique Flórez y CSIC.

Del Estal, G. 1981. "Iglesia y Constitución política en España», en C. Seco Serrano y otros, La cuestión social en la Iglesia española contemporánea: 285-332. Real Monasterio de El Escorial: Ediciones Escurialenses (Edes).

Delibes, M. 1998. El hereje. Barcelona: Destino.

Duncan, H. 1877. "The Spanish Christian Church», en J. Thomson (ed.), Report Proceedings of the First General Presbyterian Council Convened at Edinburgh, July 1877, with Relative Documents Bearing on that Affairs of the Council, and the State of the Presbyterian Churches Throughout the World: 307-308. Edinburgh: Thomas and Archibal Constable.

Estruch, J. 1968. Los protestantes españoles. Barcelona: Nova Terra.

Fernández Campos, G. 1991. Compendio cristiano español: Iglesias y misiones. London: MARC Europe. [Ed. (bilingüe) de M. Lawson].

Fernández Santos, J. 2012. Libro de las memorias de las cosas. Madrid: Cátedra.

Fliedner, F. 1874. "The Evangelization of Spain», en Ph. Schaff y S. I. Prime (eds.), History, Essays, Orations, and other Documents of the Sixth General Conference of the Evangelical Alliance, Held in New York, October 2-12, 1873: 122-126. New York: Harper \& Bros.

García Rubio, P. 1994. La Iglesia Evangélica Española. Iglesia protestante. 125 años de vida y testimonio. Barcelona: Departamento de Publicación de la IEE.

García-Mazas, J. 1962. El poeta y la escultora. La España que Huntington conoció. Pr. de Pedro Laín Entralgo. Madrid: Hispanic Society of America y Revista de Occidente.

Garrido, F. 1881. Historia das perseguições políticas e religiosas occorridas em Hespanha e Portugal, desde a edade media até aos nossos dias. Obra unica no seu genero. Vertidad do hespanhol, annotada e ampliada na parte respectiva a Portugal por L. Trindade. III. Lisboa: Emp. editora de Francisco Arthur da Silva.

González Novalín, J. L. (dir.) 1980. La Iglesia en la España de los siglos XV y XVI. Madrid: BAC. [Dir. por R. García-Villoslada].

González-Ares Fernández, J. A. 2015. Las leyes constitucionales españolas (1808-1978). [Santiago de Compostela]: Andavira Editora. [3a ed. s. I.].

Grau, J. et al. 1972. Treinta mil españoles y Dios. Barcelona: Nova Terra. Gulick, W. H. 1872. «Spain». Missionary Herald 1: 19-22.

Gutiérrez Marín, C. 1942. Historia de la Reforma en España. México: Casa Unida de Publicaciones.

Gutiérrez Martín, A. 1969. El Campo de Gibraltar en la obra evangélica española. (Cien años de historia). Barcelona: Ediciones Evangélicas Españolas.

Hernández Figueiredo, J. R. 2011. «El protestantismo en la España de la Il República a la luz de los informes del Archivo Secreto Vaticano». Hispania Sacra 127: 305-371.

How, F. D. 1900. William Conyngham Plunket, Fourth Baron Plunket and Sixty-First Archbishop of Dublin. A Memoir. London: Isbister and Company.

Hughey, D. 1985. Los Bautistas en España. Madrid: Casa Bautista de Publicaciones y Comisión de Educación y Propaganda de la UEBE. [Tr. de P. Bonet].

López Rodríguez, M. 1976. La España protestante. Crónica de una minoría marginada. Madrid: Sedmay.

López Rodríguez, M. 2002. "La asignatura pendiente: nuestra participación política», en M. García Ruiz (ed.), Iglesia y sociedad. Una aproximación desde el pensamiento protestante: 75-143. Madrid: Consejo Evangélico de Madrid.

Martínez Ruiz, J. (Azorín) 1917. Prólogo a Páginas escogidas de Leopoldo Alas (Clarín). Madrid: Casa Editorial Hernando.

Martínez, J. M. 1994. La España evangélica ayer y hoy. Esbozo de una historia para una reflexión. Viladecavalls (Barcelona): Andamio y Editorial CLIE. 
Mateos-Gago y Fernández, F. 1876. "Carta al director de El Siglo Futuro», en El Siglo Futuro, 22 de septiembre: 2-3.

Mateos-Gago y Fernández, F. 1877. Colección de opúsculos. II y III. Sevilla: Imp. y Lib. de los Sres. A. Izquierdo y sobrino.

Mayor, J. E. B. 1892. Spain, Portugal, the Bible. Cambridge: Macmillan and Bowes.

Menéndez Pelayo, M. 1986. Historia de los heterodoxos españoles. Madrid: BAC. 4 a ed.

Meyrick, F. 1905. Memories of Life at Oxford: and Experiences in Italy, Greece, Turkey, Germany, Spain, and Elsewhere. London: J. Murray.

Ministerio de Justicia. 2016. Informe anual sobre la situación de la libertad religiosa en Españ. 2015 (web).

Noyes, H. E. 1897. Church Reform in Spain and Portugal. A Short History of the Reformed Episcopal Churches of Spain and Portugal, from 1868 to the Present Time. London, Paris and Melbourne: Cassell and Company. [Introduction by the late, the Most Rev. lord Plunket, Archbishop of Dublin].

Oncins Hevia, G. 1996. "La iglesias evangélicas españolas y la masonería», en J. A. Ferrer Benimeli (coord.), Masonería y religión: convergencias, oposición, compatibilidad?: 163-176. Madrid: Editorial Complutense.

Onís, F. de 1957. "Huntington y la cultura hispánica», en Huntington 1870-1955: 19-24. Washington D. C.: Pan America Union.

Packer, J. A. 1912. Among the Heretics in Europe. With an Introduction by the Rev. John Clifford. London, New York, Toronto and Melbourne: Cassell and Company.

Peddie, R. [Mrs. Maria Denoon Peddie]. 1871. The Dawn of the Second Reformation in Spain Being the Story of Its Rise and Progress from the Year 1852. Edinburgh: Religious Tract Society.

Pérez, J. 2000. La España de Felipe II. Barcelona: Crítica. [Trad. castellana de J. Vivanco].

Pérez, J. 2002. Crónica de la Inquisición en España. Barcelona: Martínez Roca.

[Plunket, Arzobispo de Dublín]. 1894. «La relación de Lord Plun-ket» (sic), en El Siglo Futuro, 19 de octubre: 2-3.

Prescott, A. y Hottinger, S. 2006. "Algunos contactos entre la masonería española e inglesa bajo la autoridad de Sagasta», en J. Ferrer Benimeli (coord.), La masonería española en la época de Sagasta II: 847-860. XI Symposium Internacional de Historia de la Masonería Española. Logroño. 6 a 8 de julio de 2006. Zaragoza: Departamento de Educación, Cultura y Deporte.
Rico García, M. 1889. Ensayo biográfico y bibliográfico de escritores de Alicante y su provincia. Con una carta prólogo de Roque Chabás, cronista de esta provincia II. Alicante: Establecimiento tipográfico de A. Reus (con antología de poemas de Cabrera).

Ríos Sánchez, P. 1995. «Poemas satíricos aparecidos en la prensa española sobre la persona y la obra de Juan B. Cabrera, primer obispo protestante de España». Anales de Historia Contemporánea 11 (Universidad de Murcia): 295-326.

Ríos Sánchez, P. 1998. «Diálogo edificante, alegoría de Clarín sobre la intolerancia religiosa española a fines del siglo XIX». Revista de Literatura 120: 463-489.

Robles Muñoz, C. 2001. "La otra catedral y el otro obispo de Madrid». Anales de Historia Contemporánea 17 (Universidad de Murcia): 227-249.

Sanz Larrey, G. y Mayor López, C. 2006. La Masonería de la A a la Z. Madrid: Ediciones Jaguar.

Schäfer, E. H. J. 2015. Protestantismo español e Inquisición en el siglo XVI. Sevilla: CIMPE. 3 vols. EI III en dos tomos (A y B). [Trad. e intr. de F. Ruiz de Pablos, 2a ed.].

Serrano Álvarez, F. 2000. Contra vientos y mareas. Los sueños de una iglesia reformada hechos realidad. Terrassa (Barcelona): Editorial CLIE.

Tellechea Idígoras, J. I. 1977. Tiempos recios. Inquisición y heterodoxias. Salamanca: Sígueme. [Pr. de M. Bataillon].

Vilar, J. B. 1981. "Minorías protestantes bajo el franquismo (19391953)", en C. Seco Serrano et al., La cuestión social en la Iglesia española contemporánea: 335-435. El Escorial: Ediciones Escurialenses.

Vilar, J. B. 1985. «Los protestantes españoles ante la guerra civil (19361939)». Cuenta y Razón 21: 213-230.

Vilar, J. B. 1987. «Persecución contra los protestantes en la guerra civil española». Historia 16 138: 11-18.

Vilar, J. B. 1994. Intolerancia y libertad en la España contemporánea: Los orígenes de protestantismo español actual. Pr. de Raymond Carr Madrid: Istmo.

Vilar, J. B. 2001. «Los protestantes españoles: La doble lucha por la libertad durante el primer franquismo (1939-1953)». Anales de Historia Contemporánea 2001: 253-299.

Vilar, J. B. 2002. Manuel Matamoros, fundador del protestantismo española actual. Granada: Comares.

Wylie, J. A. [1870]. Daybreak in Spain; or, Sketches of Spain and Its New Reformation. A Tour of Two Months. London: Cassell, Petter and Galpin. 